\title{
Monitoring ice shelf velocities from repeat MODIS and Landsat data - a method study on the Larsen $C$ ice shelf, Antarctic Peninsula, and 10 other ice shelves around Antarctica
}

\author{
T. Haug $^{1}$, A. Kääb ${ }^{1}$, and P. Skvarca ${ }^{2}$ \\ ${ }^{1}$ Department of Geosciences, University of Oslo, P.O. Box 1047 Blindern, 0316 Oslo, Norway \\ ${ }^{2}$ Instituto Antártico Argentino, Cerrito 1248, C1010AAZ Buenos Aires, Argentina
}

Received: 21 December 2009 - Published in The Cryosphere Discuss.: 14 January 2010

Revised: 22 April 2010 - Accepted: 28 April 2010 - Published: 6 May 2010

\begin{abstract}
We investigate the velocity field of the Larsen C ice shelf, Antarctic Peninsula, over the periods 2002-2006 and 2006-2009 based on repeat optical satellite data. The velocity field of the entire ice shelf is measured using repeat low resolution MODIS data ( $250 \mathrm{~m}$ spatial resolution). The measurements are validated for two ice shelf sections against repeat medium resolution Landsat 7 ETM+ pan data $(15 \mathrm{~m}$ spatial resolution). Horizontal surface velocities are obtained through image matching using both orientation correlation operated in the frequency domain and normalized crosscorrelation operated in the spatial domain, and the two methods compared. The uncertainty in the displacement measurements turns out to be about one fourth of the pixel size for the MODIS derived data, and about one pixel for the Landsat derived data. The difference between MODIS and Landsat based speeds is $-15.4 \mathrm{~m} \mathrm{a}^{-1}$ and $13.0 \mathrm{~m} \mathrm{a}^{-1}$, respectively, for the first period for the two different validation sections on the ice shelf, and $-26.7 \mathrm{~m} \mathrm{a}^{-1}$ and $27.9 \mathrm{~m} \mathrm{a}^{-1}$ for the second period for the same sections. This leads us to conclude that repeat MODIS images are well suited to measure ice shelf velocity fields and monitor their changes over time. Orientation correlation seems better suited for this purpose because it produces fewer mismatches, is able to match images with regular noise and data voids, and is faster. Since it can match images with regular data voids it is possible to match Landsat 7 ETM+ images even after the 2003 failure of the Scan Line Corrector (SLC off) that leaves significant image stripes with no data. Image matching based on the original 12-bit radiometric resolution MODIS data produced slightly better results than using the 8-bit version of the same images. Streamline interpolation from the obtained surface velocity field on Larsen C indicates ice travel times of up to 450 to 550 years between the inland boundary and the ice shelf edge. In a
\end{abstract}

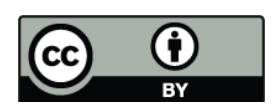

Correspondence to: T. Haug (torborg.haug@geo.uio.no) second step of the study we test our method successfully on 10 other ice shelves around Antarctica demonstrating that the approach presented could in fact be used for large scale monitoring of ice shelf dynamics.

\section{Introduction}

Velocities of glaciers, ice sheets and ice shelves can be measured successfully by remote sensing techniques. The two most commonly used methods so far have been radar interferometry and correlation of repeat images. Radar interferometry measures the phase shifts between two SAR image acquisitions. This relies on phase coherence, and in order to avoid coherence degradation on the rapidly changing snow/ice surface, tandem missions with only a few days between the acquisitions are often required. This limits the application of the radar interferometry method. Image correlation has, in principle, much longer decorrelation times. These can range from about a year for mountain glaciers to more than ten years for Antarctic glaciers and ice streams. The correlation method can be applied to both optical images and to data from synthetic aperture radar (SAR). Image matching can either be done in the spatial domain or the frequency domain (Brown, 1992; Zitova and Flusser, 2003).

Ice velocity studies using the correlation method have among others been conducted in Antarctica (e.g., Scambos et al., 1992), on Svalbard (e.g., Rolstad et al., 1997; Kääb et al., 2005), in the Alps (e.g., Kääb, 2002; Berthier et al., 2005), in New Zealand (e.g., Kääb, 2002; Quincey and Glasser, 2009), in the Himalaya (e.g., Scherler et al., 2008; Kääb, 2005), in Greenland (e.g., Strozzi et al., 2002; Howat et al., 2005), and in Patagonia (e.g., Skvarca et al., 2003). However, very few have studied ice shelf velocities using the correlation method. Bindschadler et al. (1994) and Rack et al. (1999) derived velocities using this method on the relatively small Larsen A ice shelf. Skvarca (1994) and Glasser

Published by Copernicus Publications on behalf of the European Geosciences Union. 
et al. (2009) measured the velocities of a small section of the Larsen C ice shelf as part of larger studies.

The purpose of this study is, firstly, to demonstrate that optical sensors with low spatial resolution can be used to measure the velocity fields of Antarctic ice shelves and their changes with satisfactory accuracy. Secondly, the study aims at an initial selection of ice shelves where the method presented could actually be employed for easy and operational monitoring of ice flow. Three major advantages of low resolution optical sensors such as Moderate Resolution Imaging Spectroradiometer (MODIS) or Medium Resolution Image Spectrometer Instrument (MERIS) are: (1) that they cover much larger areas with a single image than medium and high resolution optical and SAR sensors such as Landsat, SPOT, Radarsat, ERS SAR or Envisat ASAR do. This fact allows for large-scale monitoring of ice velocities. In addition, it ensures that one individual scene will in most cases contain stable ground. That helps to accurately co-register the repeat data without having to rely on the satellite-derived geolocation of the data or without having to mosaic scenes that stem from different times and contain only moving targets. (2) The very frequent coverages by low resolution satellite imagery of up to several times per day in polar regions increases drastically the potential for cloud-free scenes compared to medium and high resolution optical sensors with much lower repeat times. (3) Correlation over time for optical data is often much more robust than the phase coherence of SAR data necessary for SAR interferometry or speckle tracking, allowing to cover much larger time steps using optical data.

On the other hand, application of repeat low resolution optical images for ice shelf velocity measurements has also clear disadvantages: (1) image matching accuracy is in general governed by the pixel size so that sensors with higher spatial resolution potentially provide better accuracies. (2) Phase-based methods such as SAR interferometry and SAR speckle tracking will naturally provide a much higher displacement accuracy than image intensity correlation methods as necessary for optical data. (3) Optical sensors are unable to image during (polar) night and through cloud cover. (4) Matching of repeat optical data relies on optical surface contrast features that are naturally scarce over Antarctica. SAR backscatter features suitable for matching will often be denser.

The above list of potential advantages and disadvantages shows that measuring velocity fields on ice shelves using low resolution optical data will not be the optimal method for such work but rather represent a valuable complement to the other methods, which all have different specific benefits and limitations. Correlation of low resolution images with large coverage is a good mean to initially detect regions that have experienced changes and thus to guide where dedicated studies should be performed by collecting time series of higher resolution images.

The potential and accuracy of ice shelf velocities from low resolution optical data (here: MODIS) is assessed us-

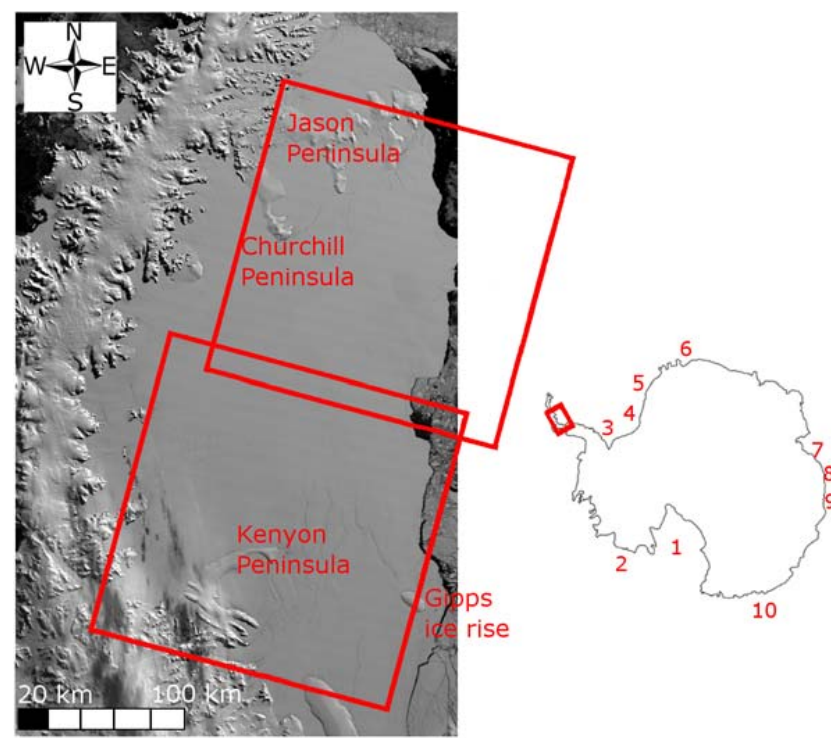

Fig. 1. Sketch map over Antarctica (right) and image of Larsen C ice shelf (left). The position of the MODIS image is indicated as red rectangle in the right panel and it forms the background in the left panel. The position of the Landsat validation images are indicated in red in the left panel (path 216 row 108 and path 216 row 107). The numbers mark the locations of the other ice shelves investigated: 1. Ross, 2. Getz east, 3. Ronne, 4. Filchner, 5. RiiserLarsen, 6. Fimbul, 7. Amery, 8. West, 9. Shackleton, 10. Mertz. The MODIS image is from 2002 and was preprocessed by Scambos et al. (2009).

ing repeat optical images of medium spatial resolution (here: Landsat). For a test site we select the Larsen $\mathrm{C}$ ice shelf and the remnants of the Larsen B ice shelf, both located on the Antarctic Peninsula (Fig. 1). The velocity measurements are conducted using two image matching methods, normalized cross-correlation which we operate in the spatial domain and orientation correlation operated in the frequency domain which we operate in the frequency domain, and these two approaches are compared. Velocities are also measured for different periods in order to identify possible velocity changes.

Rise in air and sea temperatures around the Antarctic Peninsula over the last decades have impacted on the ice shelves in this area. Turner et al. (2005) found that air temperatures on the western Antarctic Peninsula rose by $0.56^{\circ} \mathrm{C}_{\text {decade }}^{-1}$ from 1951 to 2000 . Meredith and King (2005) reported that the ocean surface temperatures on the western side of the Antarctic Peninsula increased by more than $1^{\circ} \mathrm{C}$ in the period 1955 to 1998 .

At the same time the ice shelves and glaciers in this area have undergone large changes. As many as seven ice shelves have retreated dramatically or completely disintegrated over the last decades (Cook and Vaughan, 2010). Several studies have shown that the glaciers feeding the ice shelves have increased their velocities after the disintegration. This speed up has been attributed to removal of the buttressing ice shelves 
(Rott et al., 2002; Scambos and Bohlander, 2003; De Angelis and Skvarca, 2003; Rignot et al., 2004; Scambos et al., 2004; Rignot et al., 2005). In addition, surge activity has been observed after ice shelf disintegration (De Angelis and Skvarca, 2003). The glaciers on the Antarctic Peninsula have also accelerated because their termini have thinned (Pritchard and Vaughan, 2007). As a result of the velocity increase of glaciers on the Antarctic Peninsula, glaciers in this region were considered to loose $60 \pm 46 \mathrm{Gt} \mathrm{a}^{-1}$ in 2006 , which was an increase of $140 \%$ since 1996 (Rignot et al., 2008).

Four ice shelves on the northeastern coast of the Antarctic Peninsula have disintegrated between 1986 and 2002. Larsen Inlet started the disintegration process in 1986 and it ended in 1989 (Skvarca, 1993). The ice shelf in Prince Gustav Channel collapsed between 1992 and 1995 (Rott et al., 1996). Larsen A collapsed in 1995 (Rott et al., 1996), and Larsen B followed in 2002 (Rack and Rott, 2004).

It has been observed that several of the ice shelves that disintegrated underwent large changes before they collapsed. Bindschadler et al. (1994) found that Larsen A accelerated by up to $15 \%$ from the period $1975-1986$ to the period 19861989 and Rack et al. (1999) found that it accelerated by $10 \%$ from 1986-1989 and 1988-1989 to 1992-1993. Skvarca et al. (1999) measured on Larsen B an acceleration of $13.2 \%$ between the periods 1988-1994 and 1994-1997. Rott et al. (2002) also measured an increase in velocity after a calving event in 1995. Furthermore, field measurements carried out along the center flowline of Larsen B revealed that surface ice-velocity which increased by $10 \%$ from 1996-1997 to 1997-1999 has augmented to 26\% between 1997-1999 and 1999-2001, i.e. just before the final collapse (Skvarca et al., 2004). On the other hand, Vieli et al. (2006) derived from satellite interferometry a maximum increase in ice velocity on Larsen B of about $150 \mathrm{~m} \mathrm{a}^{-1}$ from 1995/1996 to 1999.

It has been widely discussed whether the penetration of meltwater into crevasses is enhancing the fractures and thereby triggering the disintegration (Scambos et al., 2000; MacAyeal et al., 2003; Scambos et al., 2008). However, as Vieli et al. (2006) point out, this can only explain the final collapse and not the dynamic response that can be seen prior to the collapse. Because the ice shelves that have disintegrated so far have shown a dynamic response prior to the collapse, we suggest that studying changes in ice shelf dynamics can give valuable insight on their stability.

After introducing the satellite data used, we describe the image matching methods applied and their accuracy. Then, the results for Larsen $\mathrm{C}$ are presented in detail in order to understand the potential and limitations of the method. Results for ten other ice shelves in Antarctica are also described in order to evaluate the applicability and performance of the method for Antarctic ice shelves in general and to present an initial selection of ice shelves that could be monitored that way. Discussion and conclusions terminate our study.

\section{Satellite data}

Optical satellite images with two different spatial resolutions are selected for this study. Both the $250 \mathrm{~m}$ spatial resolution bands from the NASA's Moderate Resolution Imaging Spectroradiometer (MODIS) images (bands 1 and 2, bandwidths of $620-670 \mathrm{~nm}$ and $841-876 \mathrm{~nm}$, respectively) represent the lowest spatial resolution, and NASA/USGS' Landsat 7 Enhanced Thematic Mapper Plus (ETM+) panchromatic images (channel 8, bandwidth of 520-900 nm) with a spatial resolution of $15 \mathrm{~m}$ represent the highest. The MODIS images have been preprocessed by the National Snow and Ice Data Center (NSIDC) (Scambos et al., 2009). This preprocessing included orthorecitification, i.e. geocoding and topographic correction using a Digital Elevation Model (DEM). The accuracy of the topographic correction is given as better than 0.2 pixels.

Images from three different times are selected in order to measure both velocities over the two periods and velocity changes between the periods. The periods should be long enough to identify statistically significant displacements, but also short enough to avoid surface changes that hinder the correlation of images. Two areas on Larsen $\mathrm{C}$ are chosen to validate the velocities and the velocity changes measured with the MODIS imagery. These areas are hereafter referred to as Larsen C South and Larsen C North. The validation is performed by using the finer spatial resolution imagery from the Landsat ETM+ pan sensor. "Larsen C South" indicates images from path 216 row 108 and "Larsen C North" indicates images from path 216 row 107. Their location is indicated in Fig. 1. The validation areas are selected based on the availability of cloud free images from both the MODIS and the Landsat sensors with as short as possible time separation between both. An overview of the selected images can be found in Table 1.

Until autumn 2005 NSIDC produced images with 8 bit radiometric resolution from the MODIS images. Therefore the MODIS image from 2002 is 8 bit, while the images from 2006, 2008 and 2009 are 12 bit, which is the original radiometric resolution of MODIS. The images from 2006, 2008 and 2009 are also available as 8 bit images, and this gave us also the opportunity to investigate the impact of different radiometric resolutions on image matching.

Due to the small elevation differences on the Larsen ice shelf, there are only minor topographic distortions over the ice shelf caused by elevation differences in the images. These are assessed to be small enough to be neglected in this study. Co-registering the MODIS images using stable ground with varying elevation is possible because the MODIS images from NSIDC are corrected for elevation. In addition, the 2002 and 2008 MODIS data used are from the same orbit, and the 2006 and 2009 data from orbits adjacent to these so that effects from residual topographic distortion are minimized. The matched Landsat images have the same imaging geometry because they are from the same path and row, i.e. 
Table 1. MODIS and Landsat satellite images used for the velocity measurements. Larsen C South indicates Landsat images from path 216 row 108 and Larsen C North indicates Landsat images from path 216 row 107.

\begin{tabular}{cccc}
\hline \multicolumn{2}{c}{ Larsen C South } & \multicolumn{2}{c}{ Larsen C North } \\
MODIS & Landsat & MODIS & Landsat \\
\hline 17 Mar 2002 1345 & 22 Nov 2001 & 17 Mar 2002 1345 & 15 Apr 2002 \\
5 Jan 2006 1355 & 4 Jan 2006 & 5 Jan 2006 1355 & 4 Jan 2006 \\
1 Jan 2009 1330 & 12 Jan 2009 & 28 Nov 2008 1345 & 11 Dec 2008 \\
\hline
\end{tabular}

orbit position, and accurate co-registration is thus possible without prior orthorectification.

\section{Image matching methods}

\subsection{Normalized cross-correlation}

Matching of two images can be done using the image intensities directly in the normalized cross-correlation method (NCC). The first image is taken as the reference image, and a sub-window of this image is searched for in the second image, or the search image. The cross-correlation surface $\mathrm{CC}$ is given by

$$
\mathrm{CC}(i, j)=\frac{\sum_{k, l}\left(s(i+k, j+l)-\mu_{s}\right)\left(r(k, l)-\mu_{r}\right)}{\sqrt{\sum_{k, l}\left(s(i+k, j+l)-\mu_{s}\right)^{2} \sum_{k, l}\left(r(k, l)-\mu_{r}\right)^{2}}}
$$

where $(i, j)$ indicates the position in the search area, $(k, l)$ the position in the reference area, $r$ the pixel value of the reference chip, $s$ the pixel value of the search chip, $\mu_{r}$ the average pixel value of the reference chip and $\mu_{s}$ the average pixel value of the search chip. The peak of the cross-correlation surface indicates the displacement between the images.

This method has been widely used for measuring the displacement of both glaciers and rockglaciers (e.g., Kääb, 2002, 2005; Kaufmann and Ladstädter, 2003; Debella-Gilo and Kääb, 2010).

\subsection{Orientation correlation}

The second matching method is based on the orientation correlation method (OC), which is developed by Fitch et al. (2002). We conduct the matching in the frequency domain. Matching in the frequency domain works with the image frequencies instead of working directly with the image intensities. Correlation and convolution are related operations, and convolution in the spatial domain equals multiplication in the Fourier domain (the convolution theorem) (McClelland et al., 2003).

When using OC new orientation images are created from the original images based on the image intensity differences in both the horizontal $x$ direction and in the vertical $y$ direction. Central differences are used, except at the edges where forward and backward differences are used to maintain the image size. Taking $f$ as the image at time $t=1$ and $g$ as the image at time $t=2$, and choosing a complex representation, the orientation images $f_{o}$ and $g_{o}$ are created from

$$
\begin{gathered}
f_{o}(x, y)=\operatorname{sgn}\left(\frac{\partial f(x, y)}{\partial x}+i \frac{\partial f(x, y)}{\partial y}\right) \\
g_{o}(x, y)=\operatorname{sgn}\left(\frac{\partial g(x, y)}{\partial x}+i \frac{\partial g(x, y)}{\partial y}\right) \\
\text { where } \operatorname{sgn}(x)= \begin{cases}0 & \text { if }|x|=0 \\
\frac{x}{|x|} & \text { otherwise }\end{cases}
\end{gathered}
$$

where sgn is the signum function and $i$ is the complex imaginary unit. The new images $f_{o}$ and $g_{o}$ are complex and hence consist of one real and one imaginary part, where the intensity differences in the $x$ direction represent the real matrix and the intensity differences in the $y$ direction represent the imaginary matrix. The orientation images are divided into matching windows before the matching is conducted. Such windows should be small enough to avoid having different displacements inside the same window, but large enough to get a clear correlation maximum. In this study we use matching windows of $44 \times 44$ pixels $(11000 \mathrm{~m})$ for the MODIS imagery and $350 \times 350$ pixels $(5250 \mathrm{~m})$ for the Landsat imagery. The spacing between the matching windows is the same as the size of the windows to give a densely populated grid with non-overlapping, independent measurements. The correlation surface $P(x, y)$ is then computed from

$P(x, y)=\operatorname{IFFT}\left(\frac{F_{o}(u, v) G_{o}^{*}(u, v)}{\left|F_{o}(u, v) G_{o}^{*}(u, v)\right|}\right)$

where $F_{o}(u, v)$ is the Fast Fourier Transform (FFT) of the reference window from $f_{o}(x, y), G_{o}^{*}(u, v)$ is the complex conjugate of the FFT of the search window from $g_{o}(x, y)$ and IFFT is the Inverse Fast Fourier Transform. The shift that is needed to register the two matching windows is found from the position of the maximum of the correlation surface $\left(P(x, y)_{\max }\right)$.

Subpixel accuracy is obtained following the method of Argyriou and Vlachos (2007). Subpixel displacements in the $x$ direction $d x$ and in the $y$ direction $d y$ are found using

$$
\begin{aligned}
& d x=\frac{P\left(x_{m}+1, y_{m}\right)-P\left(x_{m}-1, y_{m}\right)}{2\left(2 P\left(x_{m}, y_{m}\right)-P\left(x_{m}+1, y_{m}\right)-P\left(x_{m}-1, y_{m}\right)\right)} \\
& d y=\frac{P\left(x_{m}, y_{m}+1\right)-P\left(x_{m}, y_{m}-1\right)}{2\left(2 P\left(x_{m}, y_{m}\right)-P\left(x_{m}, y_{m}+1\right)-P\left(x_{m}, y_{m}-1\right)\right)}
\end{aligned}
$$

where $P\left(x_{m}, y_{m}\right)$ is the maximum correlation value. This means that a parabolic function is fitted to the maximum point and the two surrounding points. When dividing by the amplitude in Eq. (5), only the phase of the FFT is kept. This makes the correlation peak narrower and hence the subpixel accuracy better.

When matching the Landsat images, the orientation images are low pass filtered in the Fourier domain using a Hamming-window based finite impulse response (FIR) filter. 


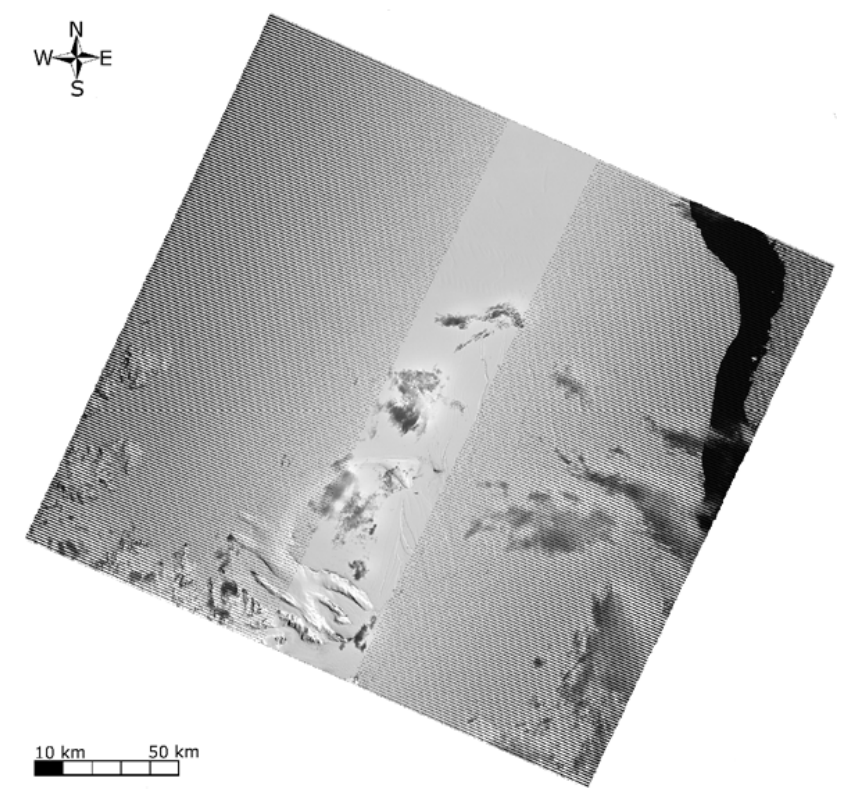

Fig. 2. Landsat 7 ETM+ pan image from 2006 path 216 row 108 used in this study that shows the regular cross-track data voids caused by the failure of the Scan Line Corrector.

This is done to remove the high frequencies, and after this filtering the images can be matched using smaller matching windows than before the filtering is conducted. This implies that the low frequencies contain the displacement information and that the high frequencies represent noise in this particular case.

Fourier domain methods have some constraints. Firstly, displacements larger than half the window size cannot be measured directly due to the quadrant ambiguity problem. If larger displacements are expected, the images should be aligned beforehand based on the expected displacement. Secondly, the window sizes have generally to be larger than if the matching is done in the spatial domain.

The clear advantages of frequency domain over spatial domain methods are that they can be fast if FFT is used, and that they are not sensitive to image information which is constrained to few frequencies. In this study that fact turns out to be particularly useful, because the Landsat 7 ETM+ images from 2003 and onward have regular cross-track data voids, i.e. voids with a very specific frequency (Fig. 2), after a failure of the Scan Line Corrector (SLC).

\subsection{Locational accuracy}

This section tries to quantify (i) the errors from coregistration and (ii) the errors in areas where no ground control is available.

To quantify the uncertainty of the matching methods, matching points over stable ground are investigated. We searched the shift measurements in both $x$ and $y$ direction
Table 2. Root mean square error (RMS) of displacement measurements obtained using frequency domain matching over stable ground. The number of measurements is indicated by $n$.

\begin{tabular}{lrrr}
\hline Image pair & $\begin{array}{r}\mathrm{RMS}_{\mathrm{x}} \\
\mathrm{m}\end{array}$ & $\begin{array}{r}\mathrm{RMS}_{\mathrm{y}} \\
\mathrm{m}\end{array}$ & $n$ \\
\hline MODIS 2002-2006 & 28.0 & 38.7 & 106 \\
MODIS 2006-2008 & 24.2 & 26.0 & 188 \\
MODIS 2006-2009 & 21.2 & 35.9 & 176 \\
MODIS 2002-2009 & 30.0 & 36.1 & 183 \\
Landsat 2001-2006 South & 4.72 & 8.00 & 71 \\
Landsat 2006-2009 South & 7.75 & 10.6 & 47 \\
Landsat 2002-2006 North & - & - & - \\
Landsat 2006-2008 North & - & - & - \\
\hline
\end{tabular}

for trends. Only zeroth order trends (i.e. mean horizontal shifts) are found to influence our level of accuracy, and these translations are therefore subtracted from the measured pixel shifts. The pixel shifts are in the order of meters for most of the MODIS images. The only exception is the 2002 image which is shifted $465 \mathrm{~m}$ relative to the others. For Landsat the shifts range from $6 \mathrm{~m}$ to $55 \mathrm{~m}$. The uncertainty of the matching methods is given by the root mean square error (RMS) of the pixel shifts of stable ground, see Table 2. Note, that the pixel location errors resulting from errors in the DEM used for orthorectifying of the MODIS data are systematic in direction (cross-track; roughly east-west), but small (less than 0.2 pixels) and with a random sign from DEM elevations being both too high and too low.

The Landsat images over Larsen C North from Table 1 and Fig. 1 cover not enough stable ground to detrend the data. Instead, images from the neighbour path 217 row 106 are used to co-register the images. These neighbour images are taken on 6 April 2002 and 11 January 2006. They overlap with some of the same grounded, low-velocity ice shelf area as the Larsen C North images. In addition they contain stable ground so that they can be co-registered. These neighbour images (i.e. path 217 row 106) are first co-registered using the stable ground present. Then, the ice velocities over the grounded low-velocity area are found, and these velocities are finally used to co-register the Larsen C North images applied in this study. Because the mean velocity is $12 \mathrm{ma}^{-1}$ the error arising from assuming identical velocity in 20062009 is considered small enough for this use. Matching of another neighbour image pair, 3 February 2006 and 25 December 2008 from path 218 row 107, confirmed the 20062008 velocities from Larsen C North with a mean difference of $-1.9 \mathrm{~m} \mathrm{a}^{-1}$. The uncertainty is considered to be somewhat higher than for the Landsat images with stable ground present in the images, and a maximum uncertainty of $15 \mathrm{~m}$ in both $x$ and $y$ direction in both periods is assumed.

Outside the areas with stable ground, the attitude variations (variations in the roll, pitch and yaw) of the satellite 
may contribute to reduced accuracy. The potential for reduced accuracy can be analyzed based on the characteristics of the sensors. Sensors aboard MODIS and Landsat are whiskbroom sensors that scan pixel by pixel unlike linear array pushbroom sensors. Data from whiskbroom systems are therefore exposed to both along-track and cross-track geometrical distortions due to attitude variations. These errors are not fully accounted for in the RMS of stable ground, because this RMS only comes from limited areas in the images. Wolfe et al. (2002) estimate the geolocation accuracy for MODIS to be $50 \mathrm{~m}$. For Landsat the geolocation accuracy is $250 \mathrm{~m}$ and the image-to-image registration accuracy is $7.3 \mathrm{~m}$ according to NASA (1996). Lee et al. (2004) confirmed that the image-to-image registration accuracy is within, and actually better, than the pre-launch requirement.

In the measured displacements over stable ground and over the ice shelf, obvious matching outliers are removed manually. Because there is displacement variation over the ice shelf, but not over the stable ground, it is possible that somewhat fewer of the mismatches are filtered out over the ice shelf compared to the stable ground. It is therefore possible that the accuracy decreases slightly over the ice shelf. This effect is, however, difficult to quantify.

Mismatches could also be removed automatically using the signal-to-noise ratio (SNR) because correct matches have generally a stronger correlation peak compared to erroneous matches. In this study, a threshold of approximately RMS $>5$ would have removed most of the erroneous matches and left most of the correct matches. However, SNR is not used in this test study because we wanted to have full control over the selection process to avoid removal of any correct matches.

Subsequently, we estimate the total uncertainty of our displacement measurements to be the root sum square (RSS) of (i) the RMS of the matches on stable ground and (ii) the above image-to-image registration accuracy. The RMS from matching over stable ground and the registration accuracy are then assumed to be independent. Since this image-to-image registration accuracy is not known to us for MODIS we use the total geolocation accuracy of $50 \mathrm{~m}$ for this sensor instead. That way, our uncertainty estimate for MODIS resembles a worst-case scenario. It is assumed that all the individual displacement matchings are dependent $(n=1)$, which is a second accuracy worst-case scenario.

A further algorithm test could have been performed by resampling the $15 \mathrm{~m}$ Landsat data to the $250 \mathrm{~m}$ MODIS resolution and comparing the matching results based on both resolution levels of the else identical images. This test was, however, not possible in our study due to the SLC off data voids in the Landsat data that dominated any resampled product.

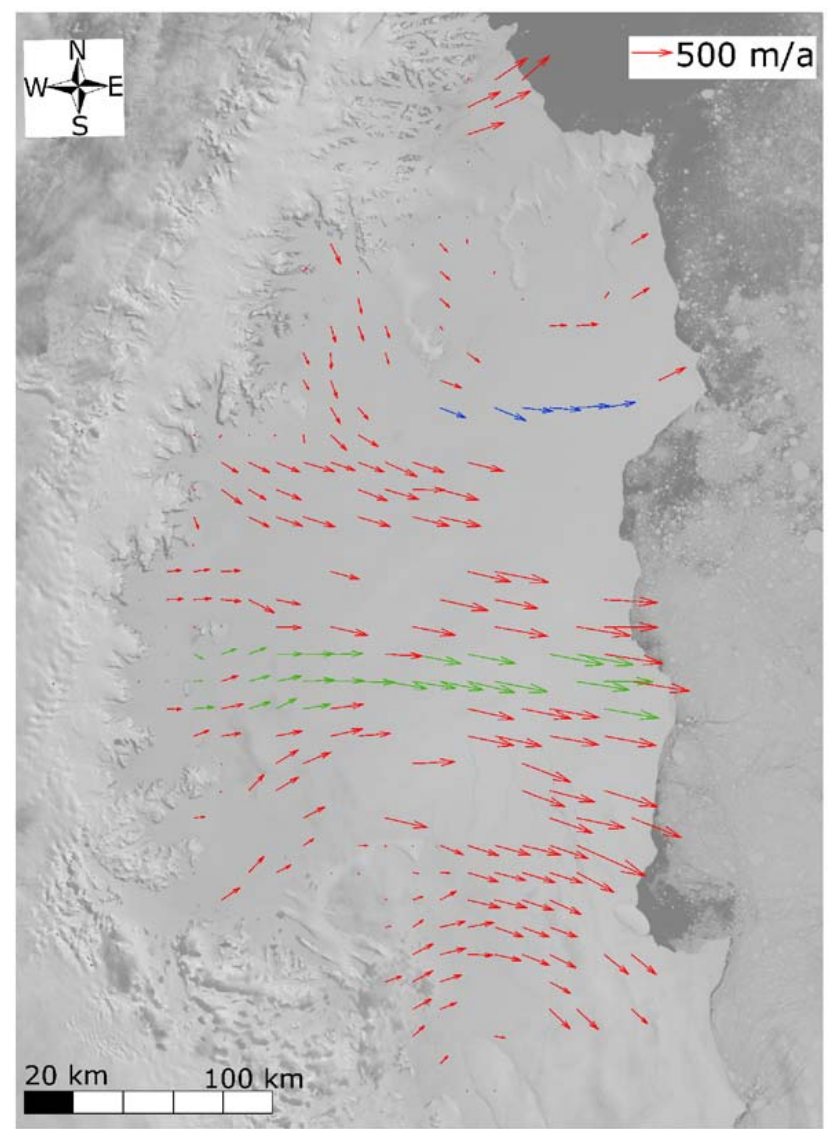

Fig. 3. Average annual velocity between 2002 and 2006 measured with orientation correlation on MODIS images. Blue and green colors indicate that these measurements are compared with Landsat measurements. The underlying MODIS image of 2009 is preprocessed by Scambos et al. (2009).

\section{Results for Larsen C}

\subsection{Orientation correlation}

OC produces a densely populated network of correct matches between the MODIS images from 2002 and 2006 (Fig. 3) and in particular between the MODIS images from 2006 and 2009 (Fig. 4). Also the two images from 2002 and 2009, nearly seven years apart, are correctly matched for most of the ice shelf (Fig. 5). The ice flows relatively slowly in the inner parts of the ice shelf and accelerates as it approaches the ice shelf edge to the east, as is to be expected. We found highest velocities for the central to southern outer part of the ice shelf, with velocities of approximately $700 \mathrm{~m} \mathrm{a}^{-1}$. The directions of the flow generally fit the crevasse pattern and the peninsulas.

The displacements derived from MODIS images for the period 2002-2006 and the period 2006-2009 are summed up and compared with displacements directly derived from the MODIS images of 2002 and 2009. Only windows that 
Table 3. Average velocity and velocity difference measured from MODIS and Landsat images for 6 points in the Larsen C North section and 28 points in the Larsen C South section. The RMS of the average is also given.

\begin{tabular}{lcccccc}
\hline & $\begin{array}{c}\text { Average velocity } \\
\text { 1st period } \\
\text { south } \\
\mathrm{m} \mathrm{a}^{-1}\end{array}$ & $\begin{array}{c}\text { Average velocity } \\
\text { 2nd period } \\
\text { south } \\
\mathrm{m} \mathrm{a}^{-1}\end{array}$ & $\begin{array}{c}\text { Average acceleration } \\
\text { 2nd period-1st period } \\
\text { south } \\
\mathrm{m} \mathrm{a}^{-1}\end{array}$ & $\begin{array}{c}\text { Average velocity } \\
\text { 1st period } \\
\text { north } \\
\mathrm{m} \mathrm{a}^{-1}\end{array}$ & $\begin{array}{c}\text { Average velocity } \\
\text { 2nd period } \\
\text { north } \\
\mathrm{m} \mathrm{a}^{-1}\end{array}$ & $\begin{array}{c}\text { Average acceleration } \\
\text { 2nd period-1 st period } \\
\text { north } \\
\mathrm{m} \mathrm{a}^{-1}\end{array}$ \\
\hline MODIS & $430.2 \pm 177.9$ & $427.1 \pm 172.5$ & $-3.1 \pm 38.0$ & $383.7 \pm 22.9$ & $425.8 \pm 39.1$ & $42.0 \pm 21.3$ \\
Landsat & $445.6 \pm 157.4$ & $453.8 \pm 159.6$ & $8.2 \pm 20.9$ & $370.8 \pm 20.1$ & $397.9 \pm 30.0$ & $27.1 \pm 14.5$ \\
MODIS - Landsat & $-15.4 \pm 39.6$ & $-26.7 \pm 40.1$ & $-11.3 \pm 44.4$ & $13.0 \pm 20.5$ & $27.9 \pm 33.5$ & $14.9 \pm 22.7$ \\
\hline
\end{tabular}

Table 4. Uncertainty of the measured MODIS and Landsat displacements and accelerations. The root sum square (RSS) of the uncertainties are also given and can be compared with the deviations given in the lower row of Table 3.

\begin{tabular}{lcccccc}
\hline & $\begin{array}{c}\text { Uncertainty } \\
\text { 1st period } \\
\text { south } \\
\mathrm{m} \mathrm{a}^{-1}\end{array}$ & $\begin{array}{c}\text { Uncertainty } \\
\text { 2nd period } \\
\text { south } \\
\mathrm{m} \mathrm{a}^{-1}\end{array}$ & $\begin{array}{c}\text { Uncertainty } \\
\text { 2nd period-1st period } \\
\text { south } \\
\mathrm{m} \mathrm{a}^{-1}\end{array}$ & $\begin{array}{c}\text { Uncertainty } \\
\text { 1st period } \\
\text { north } \\
\mathrm{m} \mathrm{a}^{-1}\end{array}$ & $\begin{array}{c}\text { Uncertainty } \\
\text { 2nd period } \\
\text { north } \\
\mathrm{m} \mathrm{a}^{-1}\end{array}$ & $\begin{array}{c}\text { Uncertainty } \\
\text { 2nd period-1st period } \\
\text { north } \\
\mathrm{m} \mathrm{a}^{-1}\end{array}$ \\
\hline MODIS & \pm 18.1 & \pm 21.8 & \pm 28.3 & \pm 18.1 & \pm 21.1 & \pm 27.8 \\
Landsat & \pm 2.86 & \pm 4.96 & \pm 5.73 & \pm 6.01 & \pm 7.63 & \pm 9.71 \\
RSS & \pm 18.3 & \pm 22.4 & \pm 28.9 & \pm 19.1 & \pm 22.4 & \pm 29.4 \\
\hline
\end{tabular}

are correctly matched (from manual inspection) in all three matchings are used for the multitemporal comparison. Over the ice shelf the 7-year average displacement difference is $-36.3 \mathrm{~m}$ with an RMS of $149.6 \mathrm{~m}(n=70)$. In the flow direction the average displacement difference is $-49.0 \mathrm{~m}$ with an RMS of $183.8 \mathrm{~m}$, and in the transverse direction it is $21.5 \mathrm{~m}$ with an RMS of $141.4 \mathrm{~m}$. Over stable ground the average pixel shift is $33.5 \mathrm{~m}$ and the RMS is $44.9 \mathrm{~m}$. The uncertainty of this comparison, calculated using the RSS of the RMS over stable ground (Table 2) and the image-to-image registration accuracy from literature, is $\pm 117 \mathrm{~m}$.

Velocity measurements on the Landsat images are mostly restricted to the crevassed areas (Figs. 6 and 7). As for the MODIS-derived data, the flow directions obtained from the repeat Landsat images fit the crevasse pattern and flow obstacles, and the velocity increases as the ice moves off the inland boundary. The sections with the highest measured velocities on the MODIS images are also covered by the Landsat images. The latter images also indicate velocities of approximately $700 \mathrm{~m} \mathrm{a}^{-1}$ in this area.

In our procedure it is not possible to directly compare Landsat-derived and MODIS-derived displacements on a point-by-point base because we use different window sizes for Landsat and MODIS, and match the Landsat data in their original geometry, i.e. not geocoded and orthorectified, in order to avoid resampling artifacts. When comparing MODIS and Landsat derived velocities, we first select all MODIS points which have velocity measurements from both periods 2002-2006 and 2006-2009. Then we do the same for the Landsat points, and at last we select a subset of the Landsat and MODIS points that are less than $11 \mathrm{~km}$ apart (the length of the sides of one MODIS matching window). This results in 6 MODIS points (see blue colored arrows in Fig. 3) in the Larsen C North section and 28 MODIS points (see green colored arrows in Fig. 3) in the Larsen C South section. For every MODIS point the average of the Landsat points that have this MODIS point as their closest neighbour is calculated. The average Landsat and MODIS derived velocity is then compared. The results of the comparison can be seen in Table 3 and the uncertainties of the results in Table 4. Landsat measures higher average velocities than MODIS in the south, and lower average velocities in the north. In the south the velocities were not significantly different in the two periods, but in the north both sensors measured a velocity increase from the first period to the second period. Due to particularly little longitudinal strain in this area the acceleration observed is considered a real acceleration and not a result of a longitudinal velocity gradient that would bias the results from matching moving target features at stable matching geolocations. The RMS of the average velocities is highest in the south. This reflects the fact that the southern section covers larger velocity gradients.

A difference in average annual velocity between the periods 2002-2006 and 2006-2009 is evident from the MODIS images also for the remnants of Larsen B. The four points measured on this ice shelf reveal a mean speed increase of $135 \mathrm{~m} \mathrm{a}^{-1}$ with an RMS of $26.3 \mathrm{~m} \mathrm{a}^{-1}$. This is an increase of approximately $30 \%$. The uncertainty here is $\pm 28.3 \mathrm{~m} \mathrm{a}^{-1}$. Other velocity changes are not statistically significant (i.e. bigger than the uncertainties given in Table 4) from the MODIS measurements. 


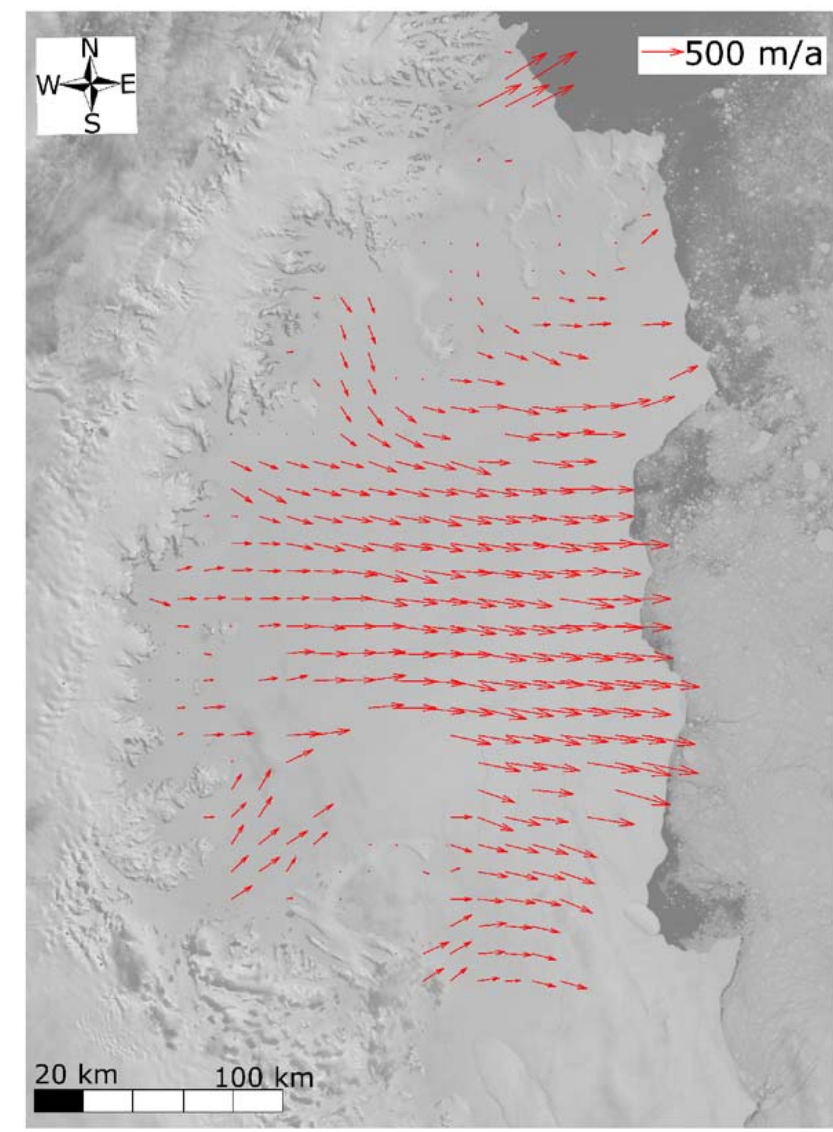

Fig. 4. Average annual velocity between 2006 and 2009 measured with orientation correlation on MODIS images.

\subsection{Comparison between orientation correlation and normalized cross-correlation}

Normalized cross-correlation (NCC) does not produce such a dense velocity field as OC when the matching is conducted in a regular grid using the same window size as used for OC ( $44 \times 44$ pixels). This can be seen if comparing Fig. 4 showing the velocity field created by the OC and Fig. 8 showing the velocity field created by NCC. These two velocity fields are obtained by matching the same images with the same position and size of the matching windows. OC produces 332 correct velocity vectors out of 471 possible $(70 \%)$, whereas NCC produces only 129 correct vectors $(27 \%)$. The RMS of the NCC measurements over stable ground are similar to the RMS of the OC measurements $(27.8 \mathrm{~m}$ in the $x$ direction and $29.5 \mathrm{~m}$ in the $y$ direction). The mean velocity difference for points on the ice shelf measured using both methods is $19.4 \pm 63.4 \mathrm{~m} \mathrm{a}^{-1}(n=75)$, OC measuring the higher velocities on average. The mean velocity difference over stable ground is $15.1 \pm 6.9 \mathrm{~m} \mathrm{a}^{-1}(n=108)$, NCC measuring the higher velocities on average. The uncertainty of the OC is $\pm 21.8 \mathrm{~m}$ and the uncertainty of the NCC is $\pm 21.5 \mathrm{~m}$.

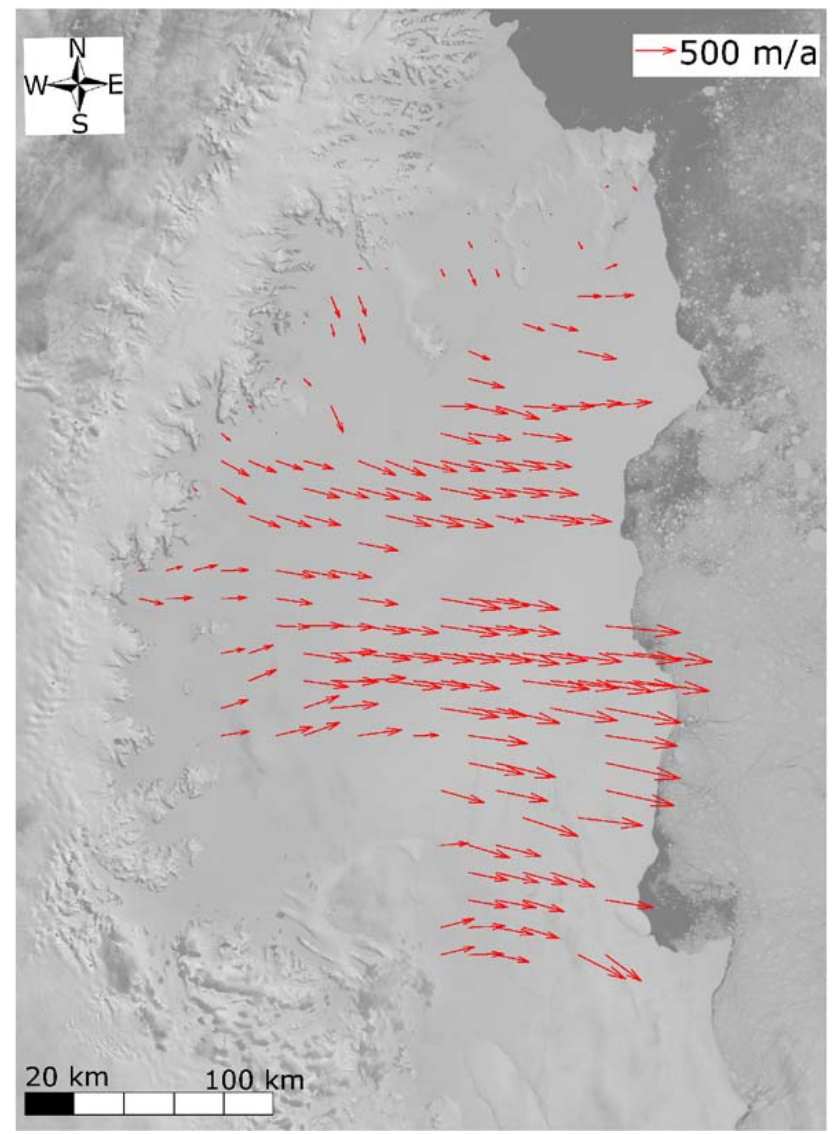

Fig. 5. Average annual velocity between 2002 and 2009 measured with orientation correlation on MODIS images.

NCC gives correct matches even if the window size is decreased. On the MODIS images, window sizes of $15 \times 15$ pixels still give correct matches in areas with good contrast, for example crevassed areas (Fig. 9). However, the RMS of the measurements over stable ground increases quickly, and when a window size of $15 \times 15$ pixels is chosen, the RMS is as high as $75 \mathrm{~m}$. Also this method measures an increase in velocity on the remnants of Larsen B from 2002-2006 to 20062009. The velocity increase is $124.4 \mathrm{~m} \mathrm{a}^{-1}$ with an RMS of $60.1 \mathrm{~m} \mathrm{a}^{-1}(n=11)$. The uncertainty of this comparison is $43.5 \mathrm{~m} \mathrm{a}^{-1}$.

\subsection{Radiometric resolution}

From autumn 2005 and onward, the MODIS images from NSIDC are also available with the original MODIS 12 bit radiometric resolution, in addition to 8 bit that are available for all dates. Both frequency and spatial domain matching methods are therefore tested on images with different radiometric resolution in order to assess matching differences between 12 bit images and 8 bit images. Matching with OC and a window size of $44 \times 44$ pixels on the 12 bit images from 5 January 2006 and 28 November 2008 produces 390 


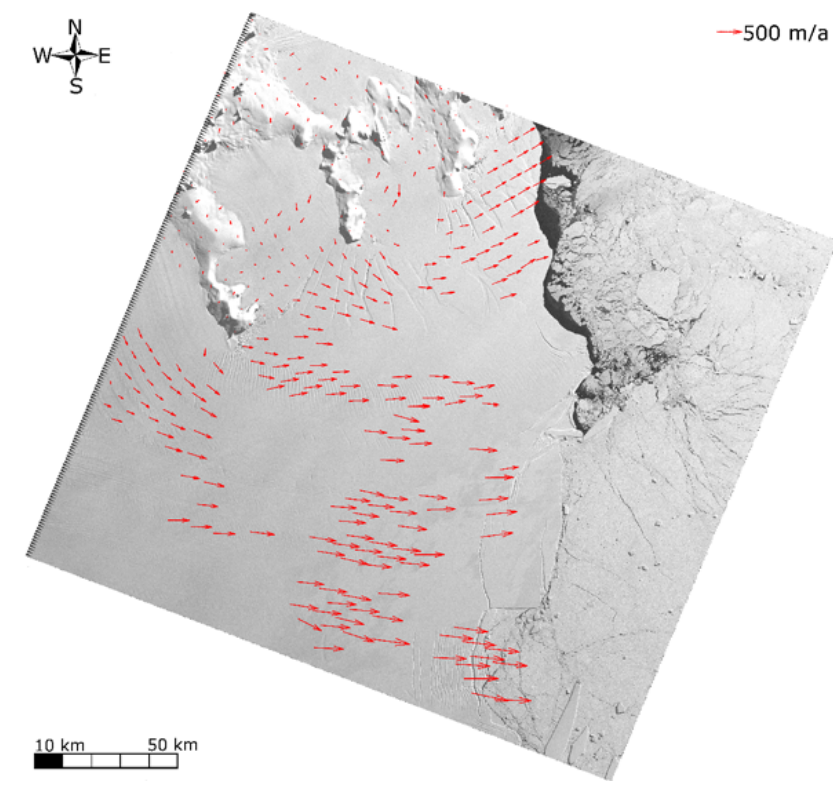

Fig. 6. Average annual velocity between 2006 and 2008 measured with orientation correlation on Landsat $7 \mathrm{ETM}+$ pan images from path 216 row 107 over Larsen C North. Underlying Landsat image of 2002 .

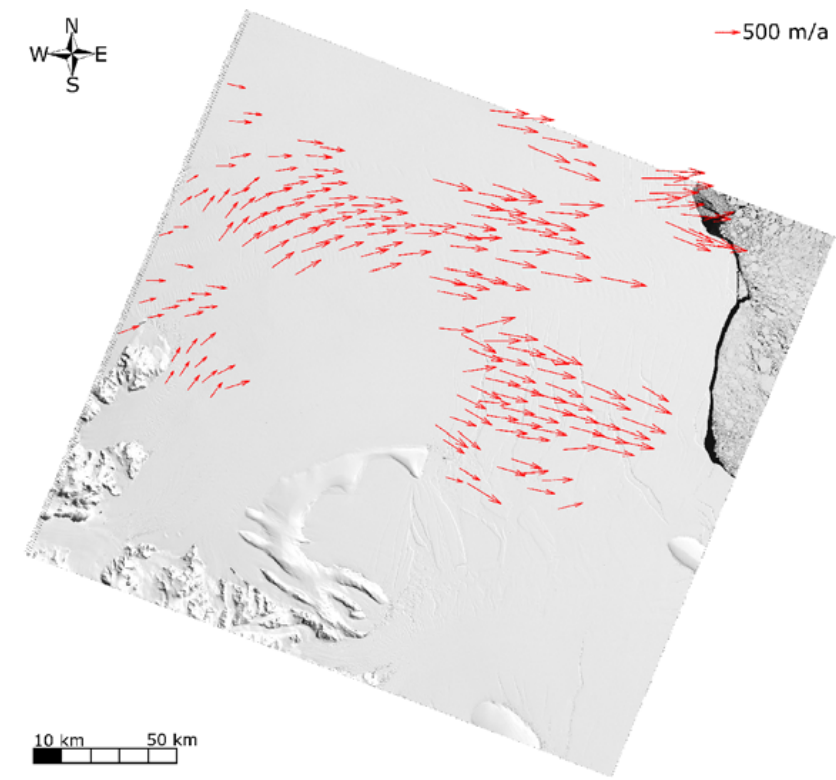

Fig. 7. Average annual velocity between 2006 and 2009 measured with orientation correlation on Landsat $7 \mathrm{ETM}+$ pan images from path 216 row 108 over Larsen C South. Underlying Landsat image of 2002 .

correct matches, whereas the 8 bit images produce 346 correct matches using the same matching windows. This means that the 8 bit images produce $11.3 \%$ fewer correct matches than the 12 bit images. A total of 7 points are correctly matched using the 8 bit images but not correctly matched us-

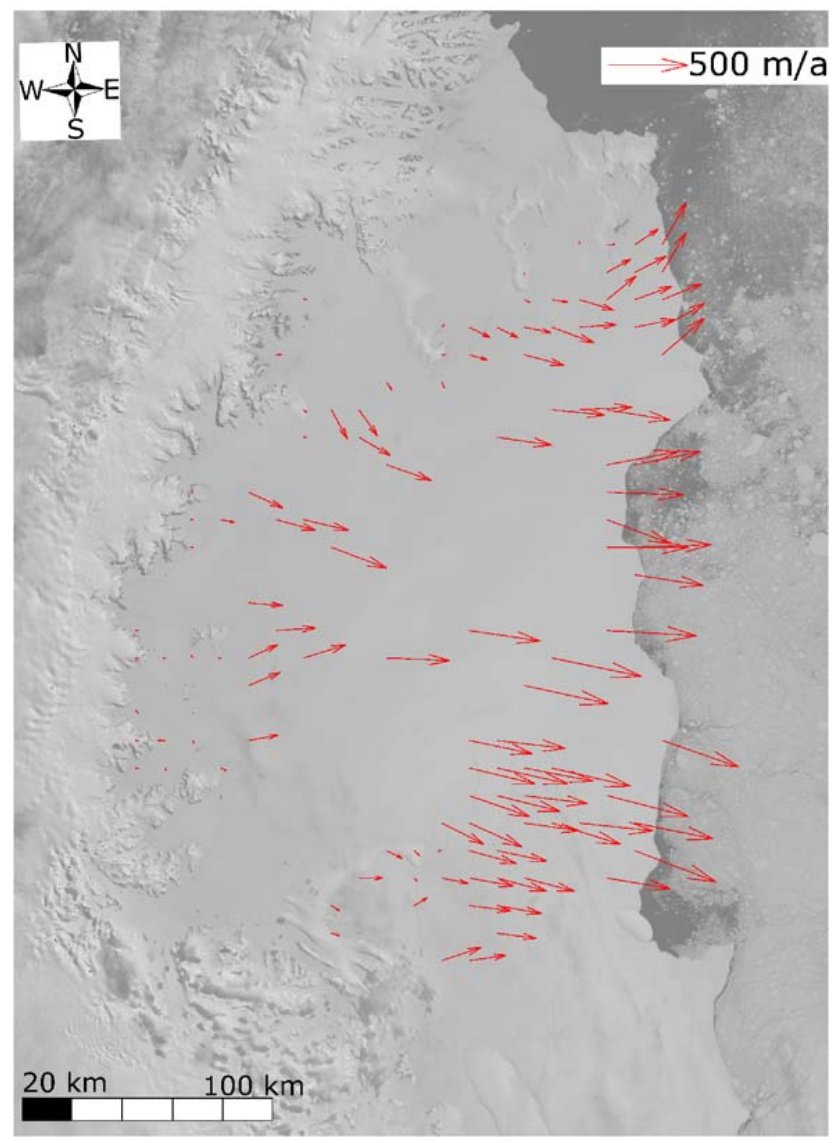

Fig. 8. Average annual velocity between 2006 and 2009 measured with normalized cross-correlation using a window size of $44 \times 44$ pixels (the same as used for the orientation correlation) on MODIS images.

ing the 12 bit images. Matching with NCC and a window size of $15 \times 15$ pixels at manually pre-selected points with good visual contrast produces 322 correct matches on the 12 bit images. When the matching is repeated at the exact same locations using the 8 bit images, 24 of these points (7.5\%) do not produce correct matches. Vice-versa, matching at manually pre-selected points using NCC on the 8 bit images gives 276 correct matches, and when the matching is repeated at the same locations using the 12 bit images, 11 of the points (4.0\%) produce mismatches. The RMS of the measurements over stable ground does not change when the 8 bit images are used instead of the 12 bit images, presumably reflecting the good contrast present over the stable areas.

\subsection{Streamlines}

Streamlines are hypothetical particle tracks interpolated from a velocity field under the assumption that the velocity field does not change over time (Kääb et al., 1998). Here, streamline starting points for time $t(0)$ are selected manually and the algorithm interpolates the velocity at these points. The 


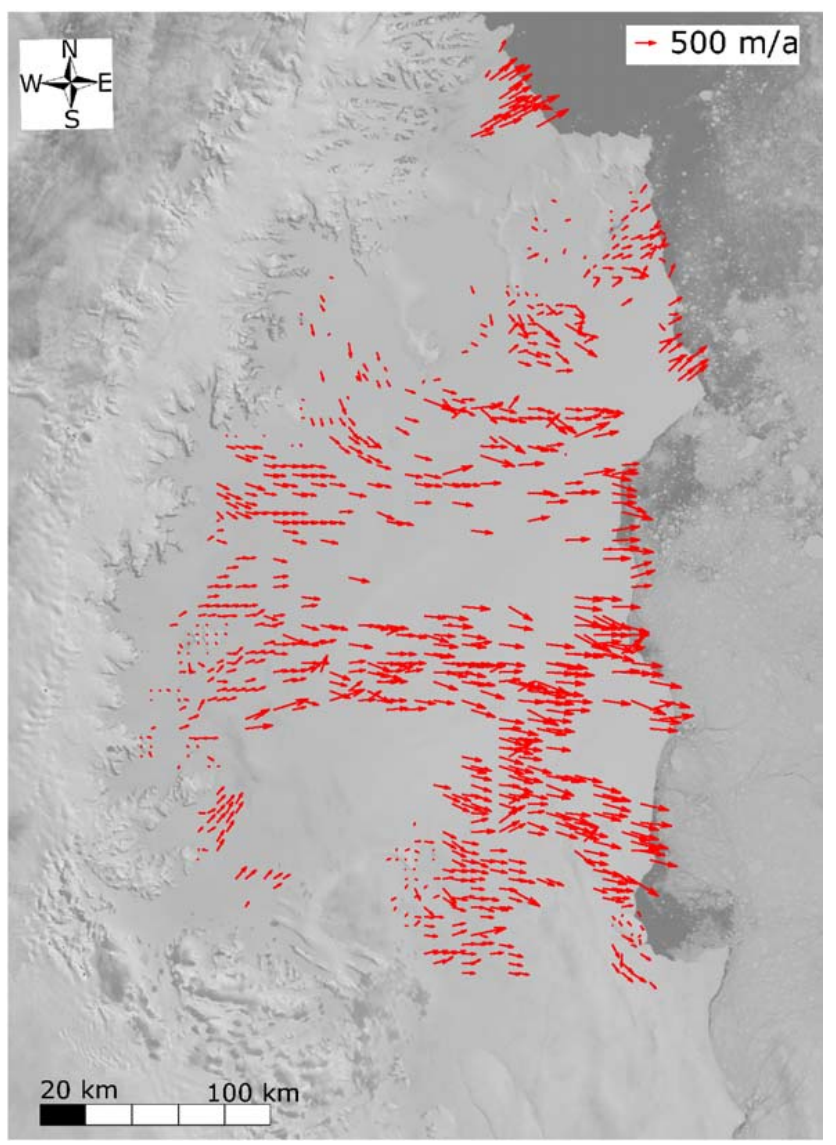

Fig. 9. Average annual velocity between 2006 and 2009 measured with normalized cross-correlation using a window size of $15 \times 15$ pixels on MODIS images.

particle position at time $t(1)$ and further for times $t(i+1)$ are computed by adding the interpolated velocity vectors to the particle position obtained from the previous iteration step. Parameters are set for the number of velocity measurements contributing to the interpolation. Thresholds are set for stopping streamline interpolation either when the velocity falls below the above velocity RMS or for an insufficient number of velocity measurements around the interpolation location. The result of the procedure is theoretical particle positions at each time step, i.e. positions with a time marker. Due to the assumption of temporal invariance of the velocity field, streamlines do not necessarily resemble real particle trajectories. Comparing computed streamlines to actual cumulative flow features such as longitudinal flowlines or crevasse patterns is an additional accuracy check, but it can also be used to indicate if and to what extent the assumption of a steady-state velocity field actually reflects reality. Lack of coincidence between the streamlines interpolated from the current velocity field with flow features reflecting past or cumulative flow conditions hints to past changes in the flow field. Streamlines can also, under the restriction that they do not resemble real particle trajectories, be used for surface age estimates.

Here, streamlines are calculated from the 2006-2009 MODIS displacement measurements. The travel time of an ice particle under present-day flow conditions, i.e. a kind of relative age of ice within the Larsen $\mathrm{C}$ ice shelf is calculated using inverse streamlines going from the ice shelf edge toward the approximate inland boundary and stopping under above thresholds (not shown). The maximum travel time is ranging from 450 years to 550 years for the central areas of the ice shelf. Along-flow streamlines starting at manual selected points around the inland boundary are also compared to the flowlines of the ice shelf (Figs. 10 and 11) to detect possible changes in the flow field. Computed streamlines and visible flowlines are mostly well aligned, confirming the high accuracy of the velocities matched, and implying at the same time that there has been no or little directional change in the ice-shelf flow over the last decades or few centuries. However, the four southernmost streamlines deviate significantly from the visible flowlines. This could be caused by systematic errors in the measurements only if the systematic errors were twice as large as the measurement uncertainty and localized to one region. The 2006-2009 velocity field has the best quality, but we also investigated the streamlines from the 2002-2006 and 2006-2008 velocity fields to see if the same deviations are present. We found that they were, but the deviations were somewhat smaller. Hence, only systematic errors in this particular part of the 2006 image could have caused the deviations if it is not caused by a real change in flow direction. A possible explanation for a change in flow direction is that one or more of the glaciers Lewis Glacier, Ahlmann Glacier, Bills Gulch and Daspit Glacier have changed their discharge and thus diverted the ice flow from their neighbours. Alternatively, or in addition, it is also possible that considerable changes in calving front position could impact the flow direction on the ice shelf. Closer investigation of this effect would, however, require calving front positions many tens or some hundreds of years back in time because the flow features observed to date might reflect such long time span. During our observational period 2002-2009, the calving front position at the end of the southern streamlines in question constantly advanced, whereas a large iceberg broke off in front of the northern streamlines in late 2004. According to Skvarca (1994), who studied the calving front position between 1975 and 1986-1989, two giant ice bergs calved off in front of the southern and middle streamlines in 1986. Also in front of the northern streamlines an ice berg broke off between 1975 and 1988.

\section{Results for other ice shelves}

In order to test the applicability and performance of the presented method for monitoring ice shelves dynamics in Antarctica in general, we also match MODIS images of other 


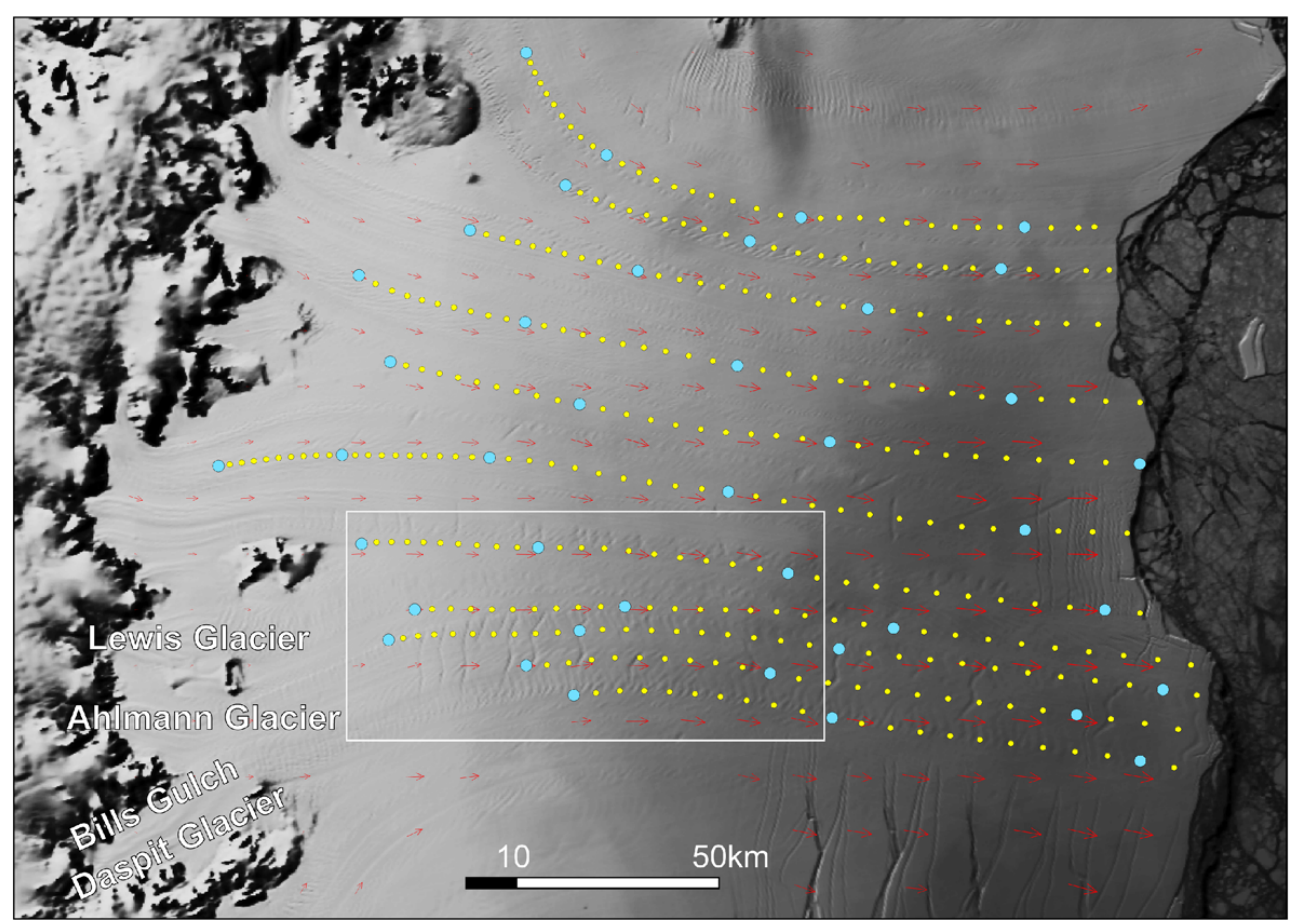

Fig. 10. Streamlines calculated from the 2006-2009 displacement measurements. Yellow dots are separated by 10 years of displacement and blue dots by 100 years of displacement. Underlying MODIS image is from 2008 and is preprocessed by Scambos et al. (2009).

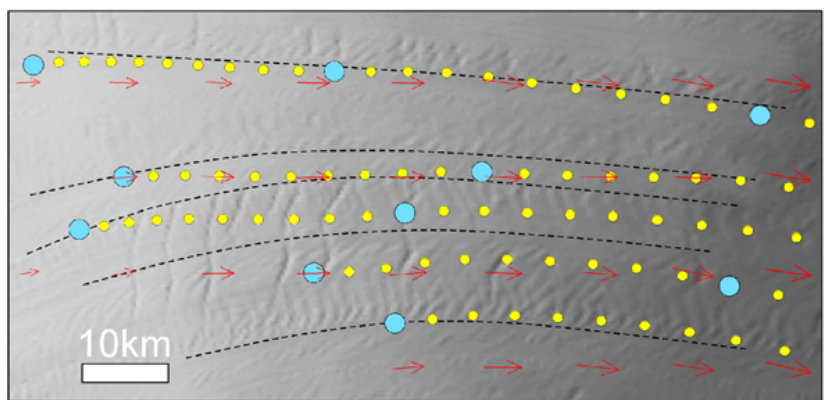

Fig. 11. Zoom-in of streamlines calculated from the 2006-2009 displacement measurements. Yellow dots are separated by 10 years of displacement and blue dots by 100 years of displacement. The black lines mark the flowlines.

ice shelves. The objective of this study step is to indicate for what ice shelves or ice-shelf sections the method works and to characterize the necessary ground conditions. Larsen C exhibits comparably many flow features, which makes the matching successful. In addition, it is also comparably fast flowing, which favours detection of displacements at a statistically significant level. Other ice shelves may be more challenging in these respects.

Velocity fields for the ice shelves Ronne, Filchner, RiiserLarsen, Fimbul, Amery, West, Shackleton, Mertz, Ross and Getz are derived. This is done for two different periods to
Table 5. MODIS images used for deriving velocities and velocity changes for ten other ice shelves in Antarctica.

\begin{tabular}{lrrr}
\hline Ice shelf & Time 1 & Time 2 & Time 3 \\
\hline Ross West & 28 Dec 2001 & 5 Dec 2005 & 8 Dec 2008 \\
Ross East & 6 Oct 2002 & 25 Oct 2005 & 27 Dec 2008 \\
Getz & 21 Jan 2003 & 1 Mar 2006 & 11 Feb 2009 \\
Ronne & 3 Dec 2002 & 4 Oct 2006 & 13 Oct 2008 \\
Filchner & 3 Dec 2002 & 23 Feb 2006 & 9 Mar 2009 \\
Riiser-Larsen & 19 Feb 2003 & 29 Jan 2006 & 14 Feb 2009 \\
Fimbul & 2 Mar 2003 & 1 Mar 2006 & 11 Mar 2009 \\
Amery & 20 Feb 2002 & 3 Mar 2006 & 19 Feb 2009 \\
West & 20 Jan 2003 & 16 Mar 2006 & 19 Mar 2009 \\
Shackleton & 26 Feb 2003 & 20 Feb 2006 & 23 Feb 2009 \\
Mertz & 15 Mar 2002 & 11 Mar 2006 & 2 Mar 2009 \\
\hline
\end{tabular}

also identify possible velocity changes. The images used are listed in Table 5. Velocity fields are shown in Figs. 12 and 13. Displacement matches are generated for the entire images shown, but non-significant displacements (i.e. displacements of the slow moving parts) are removed to improve the readability and so are also clear mismatches as revealed by manual inspection. The parts of the ice shelves not covered by velocity arrows in the figures are hence not matched correctly or show no movement. Generally the method produces densely populated velocity fields for all ice shelves. Gaps in 

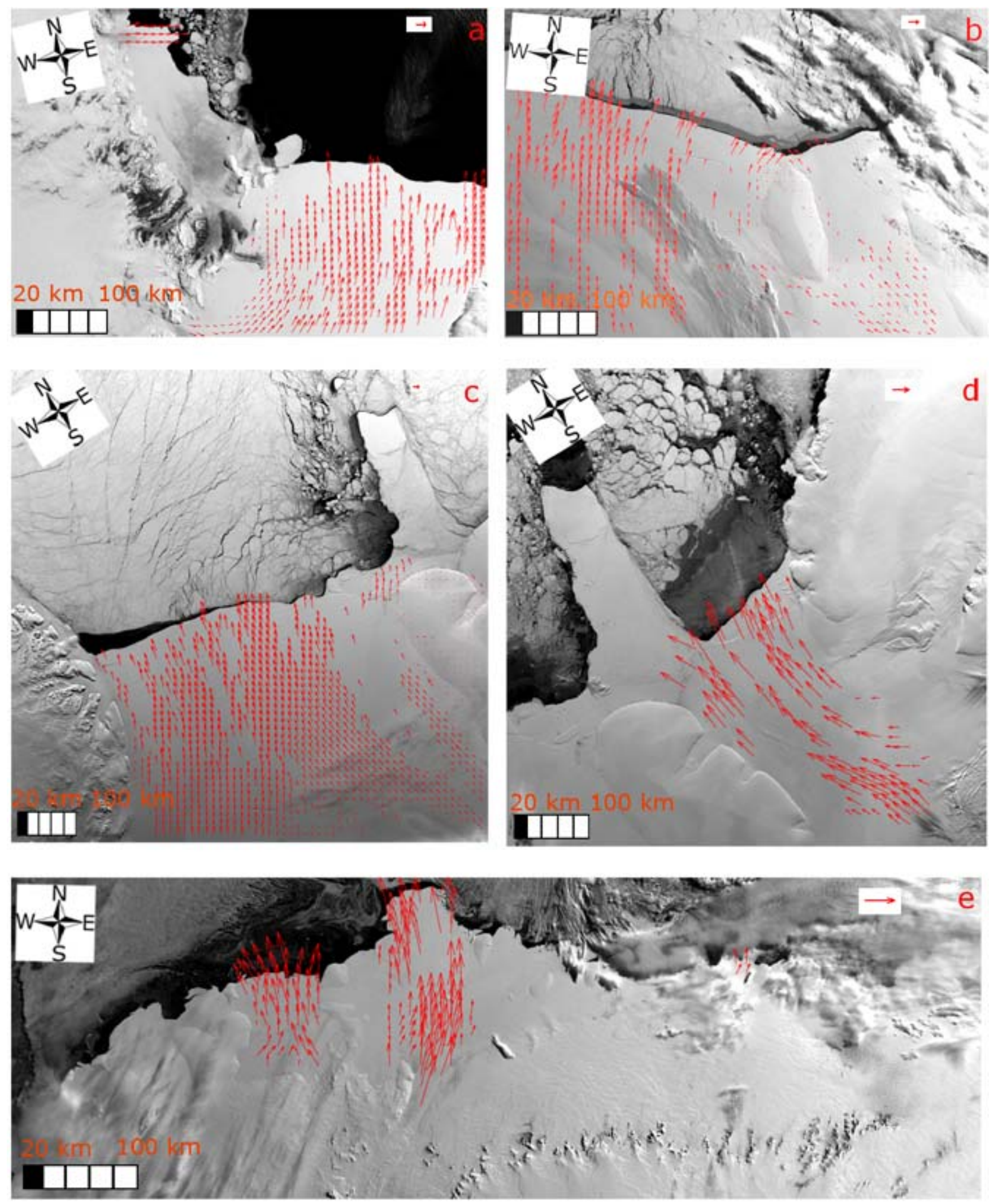

Fig. 12. The velocity fields of four ice shelves in Antarctica derived from repeat MODIS images using orientation correlation. (a) Ross (west),(b) Ross (east), (c) Ronne, (d) Filchner, (e) Fimbul. The arrow in the upper right corner indicate a velocity of $500 \mathrm{ma}^{-1}$. Note that the scale of the arrow changes from subfigure to subfigure. The underlying images are preprocessed by Scambos et al. (2009). 

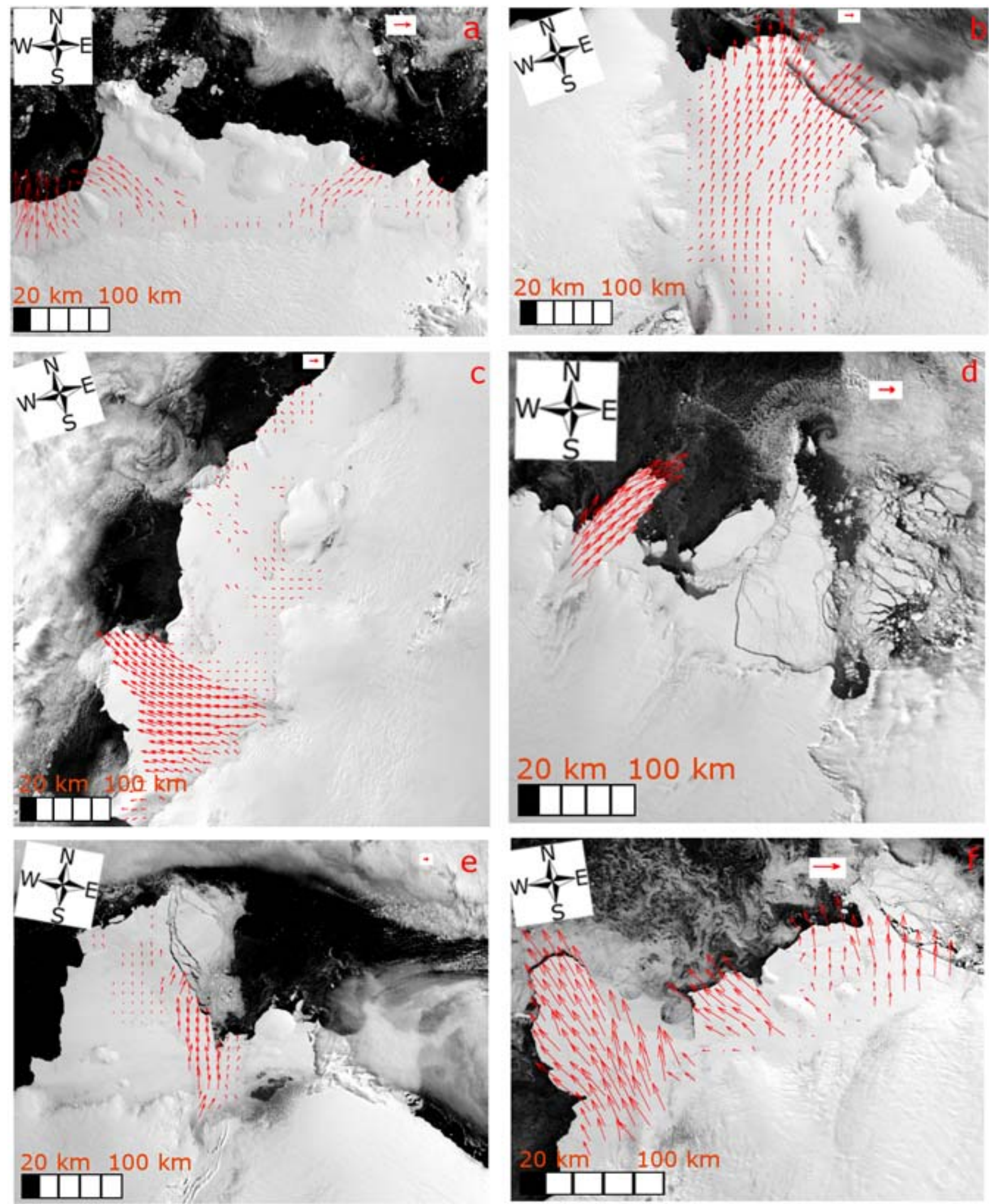

Fig. 13. The velocity fields of six ice shelves in Antarctica derived from repeat MODIS images using orientation correlation. (a) Getz (east), (b) Amery, (c) Riiser-Larsen, (d) Mertz, (e) Shackleton, (f) West. The arrow in the upper right corner indicate a velocity of $500 \mathrm{~m} \mathrm{a}^{-1}$. Note that the scale of the arrow changes from subfigure to subfigure. The underlying images are preprocessed by Scambos et al. (2009). 
the velocity fields appear mostly where too few radiometric contrast features are present. This is evident for parts of the Fimbul (Fig. 12e), Getz (east) (Fig. 13a), Riiser-Larsen (Fig. 13c) and Shackleton (Fig. 13e) ice shelves. For Ross (east) (Fig. 12b) snow dunes seem to distract the matching and thus cause mismatches, and for Filchner (Fig. 12d) there are some clouds present in the images used. We also tried to match the Wilkins and Sulzberger ice shelves, but most parts of Wilkins had too little radiometric contrast and on Sulzberger most of the velocities were too small to be significant with the level of uncertainty given by the method and image type used. Mean and maximum velocity for the ice shelves is given in Table 6 .

Three ice-shelf sections experienced small accelerations from the first period to the second period. Drygalski ice tongue northwest of Ross ice shelf (Fig. 12a) had a mean speed increase of $34.8 \mathrm{ma}^{-1}(5 \%)$. The uncertainty of this comparison is $\pm 32.4 \mathrm{ma}^{-1}$. The ice to the west of the main ice stream of Shackleton ice shelf (Fig. 13e) increased in speed by $63.8 \mathrm{ma}^{-1}(15 \%)$ with an uncertainty of $\pm 45.8 \mathrm{~m} \mathrm{a}^{-1}$. Mertz (Fig. 13d) increased its speed by $51.2 \mathrm{~m} \mathrm{a}^{-1}(4 \%)$, with an uncertainty of $\pm 42.1 \mathrm{~m} \mathrm{a}^{-1}$. Velocity measurements of Drygalski ice tongue from January 1990 to January 1992 (Frezzotti et al., 2000) are available through the Antarctic Ice Velocity Data (VELMAP) project of NSIDC (http://www.nsidc.org/data/velmap). They found that the mean speed of the ice tongue was $719 \mathrm{~m} \mathrm{a}^{-1}$, but also report that the difference between these measurements and GPS measurements was $\pm 70 \mathrm{ma}^{-1}$. This is comparable to the velocities measured in this study $\left(647 \mathrm{~m} \mathrm{a}^{-1}\right.$ from 2001-2005 and $682 \mathrm{~m} \mathrm{a}^{-1}$ from 2005-2008) because of the large uncertainties.

The western part of the West ice shelf (Fig. 13f) decelerated from the first period to the second. In the first period the mean speed was $762.1 \mathrm{~m} \mathrm{a}^{-1}$ and in the second period the mean velocity for the same points was $570.7 \mathrm{~m} \mathrm{a}^{-1}$. This corresponds to a deceleration of approximately $25 \%$. The uncertainty of this comparison is $39.5 \mathrm{~m} \mathrm{a}^{-1}$. Matching using NCC on the MODIS images and also manual matching of Landsat and ASTER images confirmed the MODIS-derived deceleration.

\section{Discussion}

The comparison between MODIS and Landsat derived velocities reveals that MODIS derived velocities are accurate enough to derive velocities for ice shelves, even for a few years of separation between the images. These velocities can also be used to study dynamic changes. This is possible, in spite of the large pixel size of $250 \times 250 \mathrm{~m}$, because the accuracy of the measurements is approximately $1 / 4$ pixel using orientation correlation.
Table 6. Mean and maximum velocity for the ten other ice shelves in Antarctica.

\begin{tabular}{lrr}
\hline Ice shelf & $\begin{array}{r}\text { Mean velocity } \\
\mathrm{m} \mathrm{a}^{-1}\end{array}$ & $\begin{array}{r}\text { Maximum velocity } \\
\mathrm{m} \mathrm{a}^{-1}\end{array}$ \\
\hline Ross & 580 & 1100 \\
Getz & 420 & 1080 \\
Ronne & 660 & 1420 \\
Filchner & 780 & 1400 \\
Riiser-Larsen & 760 & 1230 \\
Fimbul & 450 & 770 \\
Amery & 400 & 1200 \\
West & 460 & 770 \\
Shackleton & 850 & 1790 \\
Mertz & 1100 & 1340 \\
\hline
\end{tabular}

Both clouds, surface changes and lack of contrast can hinder successful matching. For the MODIS matching on Larsen C in the first period 2002-2006 it is mostly surface change between the two image acquisitions that hinders successful matching, but also lack of radiometric contrast. For the MODIS matching in the second period 2006-2009, the areas that are not correctly matched are mostly obscured by clouds. Successful matching of Landsat images is mainly hindered by the lack of radiometric contrast.

Average difference and RMS between the results when summing up the MODIS measurements from 2002-2006 and 2006-2009, and comparing them to the MODIS measurements directly for 2002-2009, are larger over the ice shelf and smaller over stable ground. The most important reason for this is that the velocity measurements are repeated on points with fixed geolocation, i.e. points that do not follow the ice movement (cf. remark on longitudinal strain in the results section, subsection on orientation correlation). Thus, longitudinal strain happening as the ice moves toward the ice shelf front is not accounted for. Another reason for the larger difference on the ice shelf is that it is easier to identify erroneous matches over stable ground than over the moving ice. It is more difficult to exclude mismatches from a nominally varying velocity field (ice shelf) than from a nominally constant one (stable ground). This is especially a problem where there are few measurements in close vicinity, which is the case for matching of the 2002 and 2009 images.

The difference in measured displacements between OC and NCC probably arises because the two methods match differently. The matching result will for instance be different if there is one strong contrast feature in the image. NCC will then match this feature, but $\mathrm{OC}$ is dependent on several features with different frequencies and with the same displacement.

Matching windows have to be chosen to be considerably larger (in pixels) for the Landsat images compared to the MODIS images in order to obtain successful matches. The 
main reason for that is due to the typical large wavelength of contrast features on Larsen $\mathrm{C}$ such as crevasses. In the case of window sizes smaller than this density, most moving window positions simply contain not enough radiometric contrast to enable successful matching. In addition, the Landsat data have to be filtered to remove high frequencies, because the Landsat 7 ETM+ pan images contain detector noise of several digital numbers (DN), much more than the MODIS data, as can easily be explored over the vast lowcontrast areas on the images. This high noise level within the $15 \mathrm{~m} \mathrm{ETM}+$ pan data compared to the $250 \mathrm{~m}$ MODIS data is a direct consequence of the much smaller instantaneous field of view and related weaker SNR in the detector. The high noise level in the ETM+ pan data requires relatively larger matching window sizes. It will be interesting to test how the potential gain in matching performance from using less noisy $30 \mathrm{~m}$ multispectral ETM+ or TM data relates to the potential loss in matching performance due to the reduced spatial resolution of $30 \mathrm{~m}$ in contrast to $15 \mathrm{~m}$. In addition, using $30 \mathrm{~m}$ data instead of $15 \mathrm{~m}$ ones would offer the possibility to applying Landsat TM5 data instead of the SLC off affected ETM+ data. Such recent TM5 data after 2003 are, though, not available for Larsen C.

Deriving velocities from MODIS and Landsat images are both based on tracking of surface features, and are hence not completely independent methods. If surface features change their shape over the observational period in a way that introduces a systematic bias, this bias would affect the displacement measurements from both methods. Only a completely independent method, which was not available to us, could rigorously test the results.

Accuracy relative to pixel size is poorer for the Landsat 7 ETM+ pan images compared to the MODIS images. This is mainly because the accuracy of the Landsat sensor is poorer, and because of the above sensor noise, which requires low-pass filtering. Low-pass filtered images give a less pronounced correlation peak, on which then the derivation of subpixel accuracy has to rely on.

OC operated in the frequency domain is better suited for image matching in this particular study. It produces more correct matches than NCC operated in the spatial domain for the MODIS images. It is capable of matching Landsat images that have regular data voids after the failure of the SLC in 2003. OC is also faster than NCC. The clearest advantage of NCC against OC is that the size of the matching windows can be smaller, and thus more independent, i.e. nonoverlapping displacements can be measured. However, reduced window size leads, in turn, to reduced accuracy. When matching low resolution images the best possible accuracy is needed in order to obtain meaningful results. In other studies where better spatial resolution of the velocity field is needed over best possible accuracy, NCC can be a better choice.

Images with 12 bit radiometric resolution are better suited for image matching in this area than images with 8 bit radiometric resolution because they produce more correct matches using both OC and NCC. It is therefore possible that areas that give no correct matches using 8 bit images can give correct matches if 12 bit images are used instead. However, 8 bit images give correct matches in most of the areas, and unless measurements over a relatively featureless area are needed, they produce satisfying results. Some points are even matched with the 8 bit images that are not matched correctly with the 12 bit images. These can be mismatches that are not revealed by our selection procedure. However, the reduced noise level in 8 bit images compared to 12 bit images from the same sensor will also lead to more robust matches in 8 bit data. In the figures, there seems to be a difference in the effect of using 12 bit images instead of 8 bit images between OC and NCC. However, this is just an apparent, not necessarily a real difference because NCC is matched on manually selected points in high-contrast areas, whereas OC is matched in a regular grid where the contrast may also be low. NCC matching in a regular grid with large window sizes gives too few matches for the MODIS images applied in our study.

It is possible that creating a 12 bit radiometric resolution image from the original 2002 MODIS data would have increased the number of MODIS matches in the first period due to more contrast. However, since the difference between 12 bit and 8 bit resolution turned out to be small, this is not done.

Co-registering images before the matching procedure improves the results, both when it comes to the accuracy of the measurements and the number of correct measurements. This is particularly important for the Landsat images which only have an absolute geolocation accuracy of $250 \mathrm{~m}$, or 16.7 pixels (NASA, 1996). In order to get more correct matches on the ice shelf, the images were sometimes also aligned locally based on an assumed first-order displacement or a first matching iteration.

In this study we only use forward tracking when we perform the matching. This means that a window from time 1 is searched for in the image from time 2 and not vice versa, which would be called backward tracking. These two different methods can potentially give different results, especially if the number of surface features is sparse. On Larsen $C$ the surface features are usually clustered, so that where there is enough contrast to get a match, this is based on several surface features. In addition the displacement is very small compared to the window size, so that it is likely that both forward tracking and backward tracking would be based on the same surface features and thus give the same results.

The presented method works well on most parts of the ice shelves investigated. The main factor that hinders successful matching during cloud-free conditions is the lack of radiometric contrast features, mostly flow features. Also snow dunes can be a problem when they cover the flow features in one of the images. Because of the uncertainty of the displacement measurements, some ice shelves actually showed velocities below the significance level. 
Both Skvarca (1994) and Glasser et al. (2009) have conducted velocity measurements on Larsen C. Skvarca (1994) found that the heavily crevassed area just north of Kenyon Peninsula (see Fig. 1 for location) moved with velocities ranging from 430 to $550 \mathrm{~m} \mathrm{a}^{-1}$ between 1975 and 1986, the velocities increasing as the ice moved seawards. In the same area we find velocities ranging from 410 to $630 \mathrm{~m} \mathrm{a}^{-1}$. Our results are therefore consistent with previous results in this area. Glasser et al. (2009) measured the velocities between 2002 and 2007 in a crevassed area close to the ice shelf edge in the middle of the ice shelf by an unspecified method. They measured a mean velocity of $640 \mathrm{~m} \mathrm{a}^{-1}$ in this area. We measure velocities of $670 \mathrm{~m} \mathrm{a}^{-1}$ in both periods, which is also consistent with their measurements in this area.

The acceleration that is observed at Larsen B and southeast of Churchill Peninsula can be put in context with the elevation decrease that Shepherd et al. (2003) measured between 1992 and 2001. The acceleration is found in the areas where also the largest elevation decrease was found. It is therefore likely that the acceleration can be attributed to the reduced backstress that a thinning ice shelf causes. This has been observed earlier for tidewater glaciers on the Antarctic Peninsula (Pritchard and Vaughan, 2007). Large calving events in front of the accelerating part could also explain the acceleration. Such calving events were searched for in the satellite images, but only a calving event in late 2004 just south of the accelerating area was found.

Glasser et al. (2009), who studied the surface structure of the Larsen $\mathrm{C}$ ice shelf from features such as crevasses and flowlines, did not see any large changes in the surface structure of the ice shelf between 1963 and 2007, and concluded that the ice shelf is stable. It is therefore likely that the acceleration seen so far in this northern part is too small to have an impact on the visible surface structures. It is important to keep in mind that Glasser et al. (2009) only looked at changes from 1963 to 2007, whereas when we compare streamlines and flowlines we can possibly see changes from the last centuries, which is the time it takes for ice to flow across the ice shelf.

The most likely explanation for the deceleration of the West ice shelf is that the ice shelf is already detached from its contributing glaciers. The satellite images support this hypothesis because there is a intersection going across the flow direction in the inner part of the ice shelf where there are no flow features. However, the detached part is probably still grounded and therefore not an iceberg.

\section{Conclusions and outlook}

We have demonstrated that repeat optical MODIS satellite images are well suited for measuring and monitoring velocities on Antarctic ice shelves in spite of their low spatial resolution of $250 \mathrm{~m}$. This is done by comparing velocities derived from MODIS images over the Larsen C ice shelf with velocities derived from Landsat 7 ETM+ pan images with a spatial resolution of $15 \mathrm{~m}$. The results agree well. For the period 2002-2006 the difference between MODIS and Landsat derived velocities are $-15.4 \mathrm{~m} \mathrm{a}^{-1}$ and $13.0 \mathrm{~m} \mathrm{a}^{-1}$ for two sections on the ice shelf, and for the period 2006-2009 it is $-26.7 \mathrm{~m} \mathrm{a}^{-1}$ and $27.9 \mathrm{ma}^{-1}$ for the same sections. The uncertainties of the method are $\pm 18.3 \mathrm{~m} \mathrm{a}^{-1}$ and $\pm 19.1 \mathrm{~m} \mathrm{a}^{-1}$ for the first period, and $\pm 22.4 \mathrm{~m} \mathrm{a}^{-1}$ and $\pm 22.4 \mathrm{~m} \mathrm{a}^{-1}$ for the second period. Uncertainties are calculated as the RSS of the RMS of the displacement measurements over stable ground and the image-to-image registration accuracy from the literature.

It is possible to obtain better results from matching MODIS images than obtained here. In this study we chose MODIS images with small amount of clouds acquired as close as possible in time to the Landsat images. Images with less clouds and of better radiometric quality were available, but then the time separation between the MODIS and the Landsat images would have been larger. Short time separation between MODIS and Landsat images was considered to be more important than maximizing the number of matches for this validation study.

Both OC operating in the frequency domain and NCC operating in the spatial domain are tested for matching the images. OC is faster, gives more correct matches, and can match images with regular noise because it is not sensitive to information restricted to few frequencies. The latter makes it possible to match Landsat 7 images with striped data voids after the failure of the SLC. NCC can match images with smaller matching window sizes than OC. However, this reduces the accuracy of the measurements. In situations where small window sizes are important, for example where the velocity varies over short distances, NCC can produce a higher resolution velocity field, but the accuracy will then be reduced. In this study both accuracy, number of correct matches and insensitivity to information constrained to few frequencies were important. Therefore OC produced the best results both for MODIS and Landsat images. In total, we achieved a sub-pixel accuracy of about $1 / 4$ of a pixel for matching displacements based on repeat MODIS data.

The remnants of Larsen B and one section in the north of Larsen C accelerated from the 2002-2006 period to the 2006-2009 period. These areas also thinned between 1992 and 2001 (Shepherd et al., 2003), which can have reduced the backstress and thereby caused the acceleration. However, these changes have so far not changed the surface structure of the ice shelf in a visually obvious way (Glasser et al., 2009).

From a deviation between calculated streamlines and flowlines visible in the MODIS images of Larsen $\mathrm{C}$ we find that there is a possible change in discharge from one or more of the glaciers Lewis Glacier, Ahlmann Glacier, Bills Gulch and Daspit Glacier. The deviation between streemlines and flowlines could also be caused by a considerable change in calving front position. For the rest of the ice shelf the streamlines and flowlines agree well, indicating stable flow direction over 
the ice particle travel time. The same streamlines indicate a travel time of the ice of the Larsen $\mathrm{C}$ ice shelf between the inland boundary and the ice edge of up to about 450 to 550 years. We applied our method successfully to ten other ice shelves around Antarctica and present an initial selection of ice shelves that could be monitored that way, confirming that the method developed here is, indeed, capable for Antarctic ice shelf velocity monitoring in general.

Our study opens for a new strategy that complements existing approaches, mainly based on SAR interferometry and tracking, to monitor and better understand dynamics, calving rates and stability of ice shelves around Antarctica. In addition to the MODIS data tested here, other low-resolution, but large coverage and high repeat-rate sensors such as ESA's Envisat MERIS are available for this purpose.

Acknowledgements. Special thanks are due to Wolfgang Rack, an anonymous referee, Mauri Pelto, and the paper's editor, Jonathan Bamber, for their detailed, thoughtful and constructive comments. MODIS data are courtesy of NASA, and were prepocessed by Scambos et al. (2009) and obtained from NSIDC through http://www.nsidc.org. Landsat data are courtesy of USGS and were obtained through http://glovis.usgs.gov. We are grateful to these institutions for making their unique data available. We are also grateful to the NASA GSFC MODIS team for their insights into MODIS orbits. This study is funded by The Research Council of Norway (NFR) through the CORRIA project (no. 185906/V30) and serves in addition as test study for the ESA DUE GlobGlacier project and the NFR IPY Glaciodyn project.

Edited by: J. L. Bamber

\section{References}

Argyriou, V. and Vlachos, T.: Quad-tree motion estimation in the frequency domain using gradient correlation, IEEE Transactions On Multimedia, 9, 1147-1154, doi:10.1109/TMM.2007.898926, 2007.

Berthier, E., Vadon, H., Baratoux, D., Arnaud, Y., Vincent, C., Feigl, K., Remy, F., and Legresy, B.: Surface motion of mountain glaciers derived from satellite optical imagery, Remote Sens. Environ., 95, 14-28, doi:10.1016/j.rse.2004.11.005, 2005.

Bindschadler, R. A., Fahnestock, M. A., Skvarca, P., and Scambos, T. A.: Surface-velocity field of the northern Larsen Ice Shelf, Antarctica, Ann. Glaciol., 20, 319-326, 1994.

Brown, L. G.: A survey of image registration techniques, Comput. Surv., 24, 325-376, 1992.

Cook, A. J. and Vaughan, D. G.: Overview of areal changes of the ice shelves on the Antarctic Peninsula over the past 50 years, The Cryosphere, 4, 77-98, 2010, http://www.the-cryosphere-discuss.net/4/77/2010/.

De Angelis, H. and Skvarca, P.: Glacier surge after ice shelf collapse, Science, 299, 1560-1562, 2003.

Debella-Gilo, M. and Kääb, A.: Sub-pixel precision algorithms for normalized cross-correlation based image matching of mass movements, Remote Sens. Environ., in review, 2010.
Fitch, A. J., Kadyrov, A., Christmas, W. J., and Kittler, J.: Orientation Correlation, in: British Machine Vision Conference, 133142, 2002.

Frezzotti, M., Tabacco, I. E., and Zirizzotti, A.: Ice discharge of eastern Dome C drainage area, Antarctica, determined from airborne radar survey and satellite image analysis, J. Glaciol., 46, 253-264, 2000.

Glasser, N. F., Kulessa, B., Luckman, A., Jansen, D., King, E. C., Sammonds, P. R., Scambos, T. A., and Jezek, K. C.: Surface structure and stability of the Larsen C ice shelf, Antarctic Peninsula, J. Glaciol., 55, 400-410, 2009.

Howat, I. M., Joughin, I., Tulaczyk, S., and Gogineni, S.: Rapid retreat and acceleration of Helheim Glacier, east Greenland, Geophys. Res. Lett., 32(22), L22502, doi:10.1029/2005GL024737, 2005

Kaufmann, V. and Ladstädter, R.: Quantitative analysis of rock glacier creep by means of digital photogrammetry using multitemporal aerial photographs: two case studies in the Austrian Alps, Proceedings of the 8th International Conference on Permafrost, 525-530, 2003.

Kääb, A.: Monitoring high-mountain terrain deformation from repeated air- and spaceborne optical data: examples using digital aerial imagery and ASTER data, ISPRS J. Photogr. Remote Sens., 57, 39-52, 2002.

Kääb, A.: Combination of SRTM3 and repeat ASTER data for deriving alpine glacier flow velocities in the Bhutan Himalaya, Remote Sens. Environ., 94, 463-474, doi:10.1016/j.rse.2004.11. 003, 2005.

Kääb, A., Gudmundsson, G. H., and Hoelzle, M.: Surface deformation of creeping mountain permafrost. Photogrammetric investigations on Rock Glacier Murtèl, Swiss Alps, Proceedings of the 7th International Conference on Permafrost, 531-537, 1998.

Kääb, A., Lefauconnier, B., and Melvold, K.: Flow field of Kronebreen, Svalbard, using repeated Landsat 7 and ASTER data, Ann. Glaciol. 42, 7-13, 2005.

Lee, D. S., Storey, J. C., Choate, M. J., and Hayes, R. W.: Four years of Landsat-7 on-orbit geometric calibration and performance, IEEE T. Geosci. Remote Sens., 42, 12, 2786-2795, doi: 10.1109/TGRS.2004.836769, 2005

MacAyeal, D. R., Scambos, T. A., Hulbe, C. L., and Fahnestock, M. A.: Catastrophic ice-shelf break-up by an ice-shelf-fragmentcapsize mechanism, J. Glaciol., 49, 22-36, 2003.

Meredith, M. P. and King, J. C.: Rapid climate change in the ocean west of the Antarctic Peninsula during the second half of the 20th century, Geophys. Res. Lett., 32, L19604, doi: 10.1029/2005GL024042, 2005.

McClellan, J. H., Schafer, R. W., and Yoder, M. A.: Signal Processing First, Pearson Education, Inc., Pearson Prentice Hall, ISBN: 0-13-120265-0, 2003

NASA, G.: Landsat 7 System Specification, NASA Goddard Space Flight Center, 1996.

Pritchard, H. D. and Vaughan, D. G.: Widespread acceleration of tidewater glaciers on the Antarctic Peninsula, J. Geophys. Res., 112, F03S29, doi:10.1029/2006JF000597, 2007.

Quincey, D. J. and Glasser, N. F.: Morphological and icedynamical changes on the Tasman Glacier, New Zealand, 19902007, Global and Planetary Change, 68, 185-197, doi:10.1016/j. gloplacha.2009.05.003, 2009.

Rack, W., Rott, H., Siegel, A., Skvarca, P.: The motion field of 
northern Larsen Ice Shelf, Antarctic Peninsula, derived from satellite imagery, Ann. Glaciol., 29, 261-266, 1999.

Rack, W. and Rott, H.: Pattern of retreat and disintegration of the Larsen B ice shelf, Antarctic Peninsula, Ann. Glaciol., 39, 505510, 2004.

Rignot, E., Casassa, G., Gogineni, P., Krabill, W., Rivera, A., and Thomas, R.: Accelerated ice discharge from the Antarctic Peninsula following the collapse of Larsen B ice shelf, Geophys. Res. Lett., 31, L18401, doi:10.1029/2004GL020697, 2004.

Rignot, E., Casassa, G., Gogineni, S., Kanagaratnam, P., Krabill, W., Pritchard, H., Rivera, A., Thomas, R., Turner, J., and Vaughan, D.: Recent ice loss from the Fleming and other glaciers, Wordie Bay, West Antarctic Peninsula, Geophys. Res. Lett., 32, L07502, doi:10.1029/2004GL021947, 2005.

Rignot, E., Bamber, J. L., Van Den Broeke, M. R., Davis, C., Li, Y., Van De Berg, W. J., and Van Meijgaard, E.: Recent Antarctic ice mass loss from radar interferometry and regional climate modelling, Nature Geosci., 1, 106-110, doi:10.1038/ngeo102, 2008.

Rolstad, C., Amlien, J., Hagen, J. O., and Lunden, B.: Visible and near-infrared digital images for determination of ice velocities and surface elevation during a surge on Osbornebreen, a tidewater glacier in Svalbard, Ann. Glaciol., 24, 255-261, 1997.

Rott, H., Skvarca, P., and Nagler, T.: Rapid collapse of northern Larsen Ice Shelf, Antarctica, Science, 271, 788-792, 1996.

Rott, H., Rack, W., Skvarca, P., De Angelis, H.: Northern Larsen Ice Shelf, Antarctica: further retreat after collapse, Ann. Glaciol., 34, 277-282, 2002

Scambos, T. and Bohlander, J.: Glaciers of Larsen B embayment area show marked speed-up since shelf collapse, Eos Trans. AGU, 86, Fall Meet. Suppl., C11C-0829, 2003.

Scambos, T., Ross, R., Bauer, R., Yermolin, Y., Skvarca, P., Long, D., Bohlander, J., and Haran, T.: Calving and ice-shelf break-up processes investigated by proxy: Antarctic tabular iceberg evolution during northward drift, J. Glaciol., 54, 579-591, 2008.

Scambos, T., Bohlander, J., and Raup, B.: "Images of Antarctic ice shelves", National Snow and Ice Data Center, online available at: http://nsidc.org/data/iceshelves $\backslash$ _images/, 2009.

Scambos, T. A., Hulbe, C., Fahnestock, M., and Bohlander, J.: The link between climate warming and break-up of ice shelves in the Antarctic Peninsula, J. Glaciol., 46, 516-530, 2000.

Scambos, T. A., Bohlander, J. A., Shuman, C. A., and Skvarca, P.: Glacier acceleration and thinning after ice shelf collapse in the Larsen B embayment, Antarctica, Geophys. Res. Lett., 31, L18402, doi:10.1029/2004GL020670, 2004.
Scambos, T. A., Dutkiewicz, M. J., Wilson, J. C., and Bindschadler, R. A.: Application of image cross-correlation to the measurement of glacier velocity using satellite image data, Remote Sens. Environ., 42, 177-186, 1992.

Scherler, D., Leprince, S., and Strecker, M. R.: Glacier-surface velocities in alpine terrain from optical satellite imagery - Accuracy improvement and quality assessment, Remote Sens. Environ., 112, 3806-3819, doi:10.1016/j.rse.2008.05.018, 2008.

Shepherd, A., Wingham, D., Payne, T., and Skvarca, P.: Larsen ice shelf has progressively thinned, Science, 302, 856-859, 2003.

Skvarca, P.: Fast recession of the northern Larsen Ice Shelf monitored by space images, Ann. Glaciol., 17, 317-321, 1993.

Skvarca, P.: Changes and surface features of the Larsen Ice Shelf, Antarctica, derived from Landsat and Kosmos mosaics, Ann. Glaciol., 20, 6-12, 1994.

Skvarca, P., Rack, W., and Rott, H.: 34 year satellite time series to monitor characteristics, extent and dynamics of Larsen B Ice Shelf, Antarctic Peninsula, Ann. Glaciol., 29, 255-260, 1999.

Skvarca, P., Raup, B., and De Angelis, H.: Recent behaviour of Glaciar Upsala, a fast-flowing calving glacier in Lago Argentino, southern Patagonia, Ann. Glaciol., 36, 184-188, 2003.

Skvarca, P., De Angelis, H., and Zakrajsek, A.: Climatic conditions, mass balance and dynamics of Larsen B ice shelf, Antarctic Peninsula, prior to collapse, Ann. Glaciol., 39, 557-562, 2004.

Strozzi, T., Luckman, A., and Murray, T.: Glacier motion estimation using SAR offset-tracking procedures, IEEE T. Geosci. Remote Sens., 40(11), 2384-2391, doi:10.1109/TGRS.2002. 805079, 2002

Turner, J., Colwell, S. R., Marshall, G. J., Lachlan-Cope, T. A., Carleton, A. M., Jones, P. D., Lagun, V., Reid, P. A., and Iagovkina, S.: Antarctic climate change during the last 50 years, Int. J. Climatol., 25, 279-294, 2005.

Vieli, A., Payne, A. J., Du, Z. J., and Shepherd, A.: Numerical modelling and data assimilation of the Larsen B ice shelf, Antarctic Peninsula, Philos. T. Roy. Soc. A, 364, 1815-1839, doi:10.1098/rsta.2006.1800, 2006.

Wolfe, R., Nishihama, M., Fleig, A., Kuyper, J., Roy, D., Storey, J., and Patt, F.: Achieving sub-pixel geolocation accuracy in support of MODIS land science, Remote Sens. Environ., 83, 31-49, 2002.

Zitova, B. and Flusser, J.: Image registration methods: a survey, Image Vision Comp., 21, 977-1000, doi:10.1016/S0262-8856(03) 00137-9, 2003. 